\title{
Gene expression analysis of Drosophilaa Manf mutants reveals perturbations in membrane traffic and major metabolic changes
}

\author{
Mari Palgi ${ }^{1,2^{*}}$, Dario Greco ${ }^{2,3}$, Riitta Lindström ${ }^{1,2}$, Petri Auvinen ${ }^{2}$ and Tapio I Heino ${ }^{1,2^{*}}$
}

\begin{abstract}
Background: MANF and CDNF are evolutionarily conserved neurotrophic factors that specifically support dopaminergic neurons. To date, the receptors and signalling pathways of this novel MANF/CDNF family have remained unknown. Independent studies have showed upregulation of MANF by unfolded protein response (UPR). To enlighten the role of MANF in multicellular organism development we carried out a microarray-based analysis of the transcriptional changes induced by the loss and overexpression of Drosophila Manf.

Results: The most dramatic change of expression was observed with genes coding membrane transport proteins and genes related to metabolism. When evaluating in parallel the ultrastructural data and transcriptome changes of maternal/zygotic and only zygotic Manf mutants, the endoplasmic reticulum (ER) stress and membrane traffic alterations were evident. In Drosophila Manf mutants the expression of several genes involved in Parkinson's disease (PD) was altered as well.

Conclusions: We conclude that besides a neurotrophic factor, Manf is an important cellular survival factor needed to overcome the UPR especially in tissues with high secretory function. In the absence of Manf, the expression of genes involved in membrane transport, particularly exocytosis and endosomal recycling pathway was altered. In neurodegenerative diseases, such as PD, correct protein folding and proteasome function as well as neurotransmitter synthesis and uptake are crucial for the survival of neurons. The degeneration of dopaminergic neurons is the hallmark for PD and our work provides a clue on the mechanisms by which the novel neurotrophic factor MANF protects these neurons.
\end{abstract}

\section{Background}

Recently characterised MANF (Mesencephalic Astrocytederived Neurotrophic Factor) and CDNF (Cerebral Dopamine Neurotrophic Factor) form an independent family of neurotrophic factors [1]. MANF was identified from a conditioned media of cultured mesencephalic astrocytes in a search for secreted factors supporting dopamine (DA) neurons [2]. Specific loss of DA neurons is the characteristic feature of Parkinson's disease (PD). Therefore factors that maintain and support DA neurons are attractive candidates for the treatment of PD. MANF was shown to support the survival of cultured primary DA neurons but to have no effect on cultured GABAergic or serotonergic

\footnotetext{
* Correspondence: mari.palgi@helsinki.fi; tapio.heino@helsinki.fi 'Department of Biosciences, University of Helsinki, PO Box 56, Viikinkaari 5, Helsinki 00014, Finland

Full list of author information is available at the end of the article
}

neurons [2]. Subsequently, mammalian MANF and its paralog CDNF were shown to prevent the loss of DA neurons in mouse 6-OHDA PD model $[3,4]$. Contrary to other vertebrate neurotrophic factors the MANF/CDNF family is evolutionarily well conserved among multicellular organisms including the fruit fly, Drosophila melanogaster $[2,3,5]$. Importantly, the protective role of MANF for DA neurons is also conserved [5]. Apparently both mammals and invertebrates share the same signalling partners as the lack of Drosophila Manf can be substituted by human MANF [5]. However, the interaction partners or how these proteins act at the molecular level are still elusive. It is important to understand the mechanisms of how these MANF/CDNF family proteins work at molecular level before the potential therapeutic applications.

Recent studies have shown the protective role of mammalian MANF (also known as ARMET) to be more

\section{Biomed Central}


general than restricted to the nervous system. MANF is upregulated by UPR in several mammalian cell lines [6-8] and by ischemia induced UPR in the heart and brain [8-10]. ER is the central regulator of protein folding and quality control and it has to adapt its capacity to the specific need of a particular cell type. Conditions challenging the function of the ER, like an increase of newly synthesized unfolded proteins in its lumen, lead to UPR [11]. In eukaryotes, the three canonical branches of UPR are mediated by ER membrane-associated sensor proteins. In stress-free, functional ER the intralumenal domains of these sensor proteins are bound to a chaperone BiP/GRP78 (Binding immunoglobulin protein/Glucose-regulated protein 78) and maintained inactive $[12,13]$. The UPR intersect with a variety of inflammatory and stress signalling pathways and networks activated by oxidative stress, all of which can influence cell metabolism. ER stress and UPR have also been implicated in the pathogenesis of several neurodegenerative diseases because of their characteristic accumulation of specific misfolded proteins [14]. Data from PD patients reveal that in DA neurons of substantia nigra the UPR is activated [15]. Recently, Drosophila has been used progressively to model human neurodegenerative diseases and UPR [16-18].

We have previously generated and characterized Drosophila Manf mutants. The zygotic null mutants (Manf $f^{496}$ ) survive up to 2nd instar larvae due to the high maternal contribution. Mutants lacking both maternal and zygotic Manf $\left(\operatorname{Manf} f^{m z \Delta 96}\right)$ are late embryonic lethal and never hatch [5]. The embryonic lack of maternal Manf gene products and the lethality is rescued by paternal Manf gene expression. Both Manf $f^{m \Delta 96}$ and Manf ${ }^{\Delta 96}$ mutants share nervous system defects, particularly dopamine neurites are altered and degenerate. Ectopic overexpression of Manf reveals no evident abnormalities in the embryonic or larval nervous system development or in the adult flies (data not shown).

Here we compare the mRNA expression profiles of Manf ${ }^{m z \Delta 66}$ mutant embryos, Manf ${ }^{\Delta 96}$ mutant larvae, paternally rescued maternal mutant embryos Manf $f^{n 96}$ / + , and Manf ubiquitously overexpressing larvae to the wild type animals of exactly the same stages.

\section{Results and discussion}

The most prevalent changes in gene expression occur in Manf mutants that lack the maternal contribution of Manf For microarray gene expression analysis we used two developmental stages in combination with three separate genotypes. The age of embryos and larvae were selected according to the lifespan of the Manf mutants. Manf ${ }^{m \Delta \Delta 96}$ mutants fail in tracheal air filling and never hatch. Mutant Manf ${ }^{n z \Delta 96}$ embryos were picked during the late stage of 17 (21-22 hours after egg laying, AEL) just before hatching when the trachea of wild type embryos fill with air. Mutant Manf ${ }^{\Delta 96}$ larvae with maternal contribution survive to approximately 75 hours AEL and were collected as first instars 29-50 hours AEL when maternal loads of Manf gene products have decreased. Three biologically independent sets of samples were used for microarray analysis. The expression profiles of all transgenic and mutant animals were compared to the wild type of the corresponding developmental stage. The numerical overview of statistically significant differences $(P<0.01)$ showed the most prominent changes in gene expression of Manf $f^{m \Delta 96}$ mutants (about $10 \%$ of genes differentially regulated). The smallest changes took place in the case of paternal rescue (less than $0.5 \%$ of genes differentially regulated) (Table 1 ). Among the differentially regulated genes, approximately half were up- or downregulated in different Manf conditions. Altogether we validated 40 genes of the microarray results. Genes were selected by several criteria such as differential expression or similar regulation in both mutants or otherwise high representation in the whole dataset. As a result, $61.5 \%$ of validated genes in different genetic conditions were independently confirmed by qPCR (Tables 2 and 3, Additional file 1: Table S1).

\section{Membrane transporters and metabolic genes are downregulated in Manf ${ }^{m z \Delta 96}$ mutants}

Development of maternal and zygotic mutant Manf $f^{m \Delta 96}$ proceeds until stage 16 with no differences to wild type embryos, but 21 hours AEL the cuticle and the nervous system defects become evident [5]. In comparison to wild type embryos of the same age, in Manf ${ }^{m z \Delta 96}$ mutants 1191 genes were found to be downregulated. These genes were grouped into 105 functional clusters (Additional file 2 ), among which the most significantly enriched clusters were related to membrane transporters ( 25 genes) and transmembrane proteins (146 genes) (Table 4). There were several enriched clusters referring to different metabolic processes such as amine, amino acid and carboxylic acid catabolic processes (11 genes), DNA metabolic processes (26 genes), and genes related to pyrimidine metabolism (15 genes).

Among the downregulated genes in Manf $f^{m z \Delta 96}$ mutants, the gene ontology (GO) term of mitochondria-related transcripts was highly enriched (28 genes). Mitochondria are the respiratory machinery of the cell responsible for oxidation processes and participate in maintaining cellular homeostasis. The lack of Manf causes downregulation of several components in all mitochondrial compartments: the lumen as well as the inner and outer membranes.

Stress and defence response related genes are induced in Manf $^{m z \Delta 96}$ mutants

In Manf ${ }^{m z \Delta 96}$ mutant embryos, 1243 genes were upregulated in comparison to wild type embryos of the same 
Table 1 Overview of microarray experiment

\begin{tabular}{|c|c|c|c|c|c|c|}
\hline comparison between genotypes & diff. reg. probes & $\%$ all probes & down reg. & $\%$ all diff. reg. & upreg. & $\%$ all diff. reg. \\
\hline Manf ${ }^{m / 196}$ vs wt stage 17 embryos & 3183 & 7.3 & 1501 & 47.2 & 1682 & 52.8 \\
\hline$\overline{M^{\prime} f^{m z} \triangle} 96 /+$ vs wt stage 17 embryos & 180 & 0.4 & 53 & 29.4 & 126 & 70.0 \\
\hline Manf $^{m z / 96}$ vs Manf $^{m z \triangle 96} /+$ stage 17 embryos & 2681 & 6.2 & 1290 & 48.1 & 1391 & 51.9 \\
\hline Manf $^{996}$ vs wt 29-50 hr AEL larvae & 1734 & 4.0 & 894 & 51.6 & 840 & 48.4 \\
\hline 69B-GAL4>UAS-Manf ${ }^{133}$ vs wt 29-50 hr AEL larvae & 1240 & 2.8 & 513 & 41.4 & 727 & 58.6 \\
\hline Manf $^{196}$ vs $69 B-G A L 4$ > UAS-Manf ${ }^{133} 29-50$ hr AEL & 2775 & 6.4 & 1615 & 58.2 & 1160 & 41.8 \\
\hline
\end{tabular}

The number of differentially regulated probes was compared. In the Agilent Drosophila microarray design $(4 \times 44 \mathrm{~K})$ there was unequal number of probes targeting the particular gene, ranging from one probe to several per gene.

stage (Additional file 3). The most prominent group of significantly enriched GO terms was immune and defense response (69 genes), followed by the groups related to proteolysis, hydrolases and peptidases (197 genes) (Table 5). The upregulated gene set was also enriched in genes related to actin cytoskeleton organization and actin filament-based process (28 genes). Moreover, genes involved in cell death ( 28 genes) were prominently enriched as well.

Enzymes for dopamine synthesis are upregulated despite of low dopamine levels

Extremely low dopamine levels are detected in Manf ${ }^{m \Delta \Delta 96}$ embryos [5]. Nonetheless, we observed significant upregulation of transcripts of the dopamine producing enzymes tyrosine hydroxylase (TH) and DOPA decarboxylase (Ddc) (Table 2). Punch; encoding a GTP cyclohydrolase, an enzyme for tetrahydrobiopterin (a cofactor for TH) synthesis was also upregulated in $\operatorname{Manf}^{m z \Delta 96}$ embryos (Table 2). There could be several explanations for these alterations. Tyrosine, the essential amino acid for dopamine synthesis, is transported into the cell from hemolymph. In Manf mutants several amino acid membrane transporters were downregulated. The lack of substrate, tyrosine, together with low amounts of the end product, dopamine, could lead to the upregulation of the genes coding for the enzymes in dopamine synthesis pathway and their cofactors.

Table 2 qPCR validation of results and microarray data obtained from stage 17 embryos

\begin{tabular}{|c|c|c|c|c|c|c|c|c|c|}
\hline \multirow[b]{3}{*}{$\#$} & \multirow[b]{3}{*}{ Gene Name } & \multirow{2}{*}{\multicolumn{2}{|c|}{$\frac{\text { microarray }}{\operatorname{lanf}^{m z \Delta 96} \text { vs } w}$}} & \multicolumn{4}{|c|}{ qPCR } & \multirow[b]{3}{*}{ gene ID } & \multirow[b]{3}{*}{ Description } \\
\hline & & & & Manf & ${ }_{7 z \Delta 96}$ vs $w$ & $69 \mathrm{~B}>1$ & $n f^{133}$ vs $w$ & & \\
\hline & & $\log \mathrm{FC}$ & P.Value & $\log 2$ & T-test & $\log 2$ & T-test & & \\
\hline 1 & CG10420 & 1.98 & 0.0001 & 5.15 & 9.7E-07 & -3.29 & $1.8 \mathrm{E}-05$ & CG10420 & Nucleotide exchange factor SIL1 precursor \\
\hline 2 & CG14879 & -4.03 & $7.3 \mathrm{E}-11$ & -3.46 & 0.0004 & & & CG14879 & Concanavalin A like lectin homology \\
\hline 3 & CG5810 & -1.92 & $1.8 \mathrm{E}-06$ & -3.78 & $1.5 \mathrm{E}-07$ & & & CG5810 & leucine rich repeat \\
\hline 4 & $D d c$ & 1.62 & $4.6 \mathrm{E}-05$ & 2.69 & 0.0003 & -4.99 & $1.6 \mathrm{E}-05$ & CG10697 & DOPA decarboxylase \\
\hline 5 & DnaJ-H & 1.10 & $4.1 \mathrm{E}-05$ & 2.56 & $2.3 \mathrm{E}-05$ & & & CG9828 & DnaJ homolog \\
\hline 6 & Hrs & 1.56 & 0.0001 & 1.38 & 0.05 & & & CG2903 & Hepatocyte growth factor-regulated tyrosine kinase substrate \\
\hline 7 & Hsp83 & 2.46 & 9.7E-05 & 4.57 & $3.2 \mathrm{E}-06$ & & & CG1242 & Heat shock protein 83, HSP90 homolog \\
\hline 8 & $\ln R$ & 1.21 & 0.0007 & 1.87 & $3.4 \mathrm{E}-05$ & & & CG18402 & Insulin-like receptor precursor \\
\hline 9 & Pak3 & -1.96 & 0.0003 & -1.14 & 0.0003 & & & CG14895 & Pak, serine threonine kinase \\
\hline 10 & Pi3K92E & 1.11 & 0.0003 & 2.34 & 0.03 & & & CG4141 & phosphatidylinositol-4-phosphate 3-kinase \\
\hline 11 & pipe & -1.53 & $4.2 \mathrm{E}-05$ & -0.25 & 0.0001 & & & CG9614 & heparan sulfate 2-O-sulfotransferase \\
\hline 12 & pale & 2.83 & $3.4 \mathrm{E}-07$ & 4.83 & $1.0 \mathrm{E}-06$ & & & CG10118 & TH; Tyrosine 3-hydroxylase \\
\hline 13 & punch & 1.97 & $4.3 \mathrm{E}-06$ & 8.41 & 0.0001 & 0.69 & 0.02 & CG9441 & punch, GTP cyclohydrolase I \\
\hline 14 & Rala & 1.48 & 1.7E-07 & 0.63 & $2.1 \mathrm{E}-05$ & & & CG2849 & Ras-related protein \\
\hline 15 & sulfateless & 4.21 & $1.8 \mathrm{E}-09$ & 1.62 & $4.3 \mathrm{E}-05$ & & & CG8339 & heparan sulfate glucosaminyl $\mathrm{N}$-deacetylase/N-sulfotransferase \\
\hline 16 & $R O P$ & 3.33 & $4.2 \mathrm{E}-10$ & 0.82 & $4.3 \mathrm{E}-05$ & & & CG15811 & Ras-opposite \\
\hline 17 & ubisnap & -0.43 & $4.4 \mathrm{E}-05$ & -1.18 & 0.001 & & & CG11173 & ubisnap, SNAP29 homolog \\
\hline 18 & DmManf & -1.37 & 0.0006 & -5.39 & $6.3 \mathrm{E}-06$ & 1.82 & $1.8 \mathrm{E}-06$ & CG7013 & Manf, known previously as Arp-like \\
\hline
\end{tabular}

Only statistically significant results $(\mathrm{P}<0.05)$ are presented. Results of qPCR were made comparable to microarray fold change (FC) by calculating the log 2 from the relative fold changes. T-test means calculated P-value associated with Student's t-Test. 
Table 3 qPCR validation of results and microarray data obtained from 29-50 hr larvae

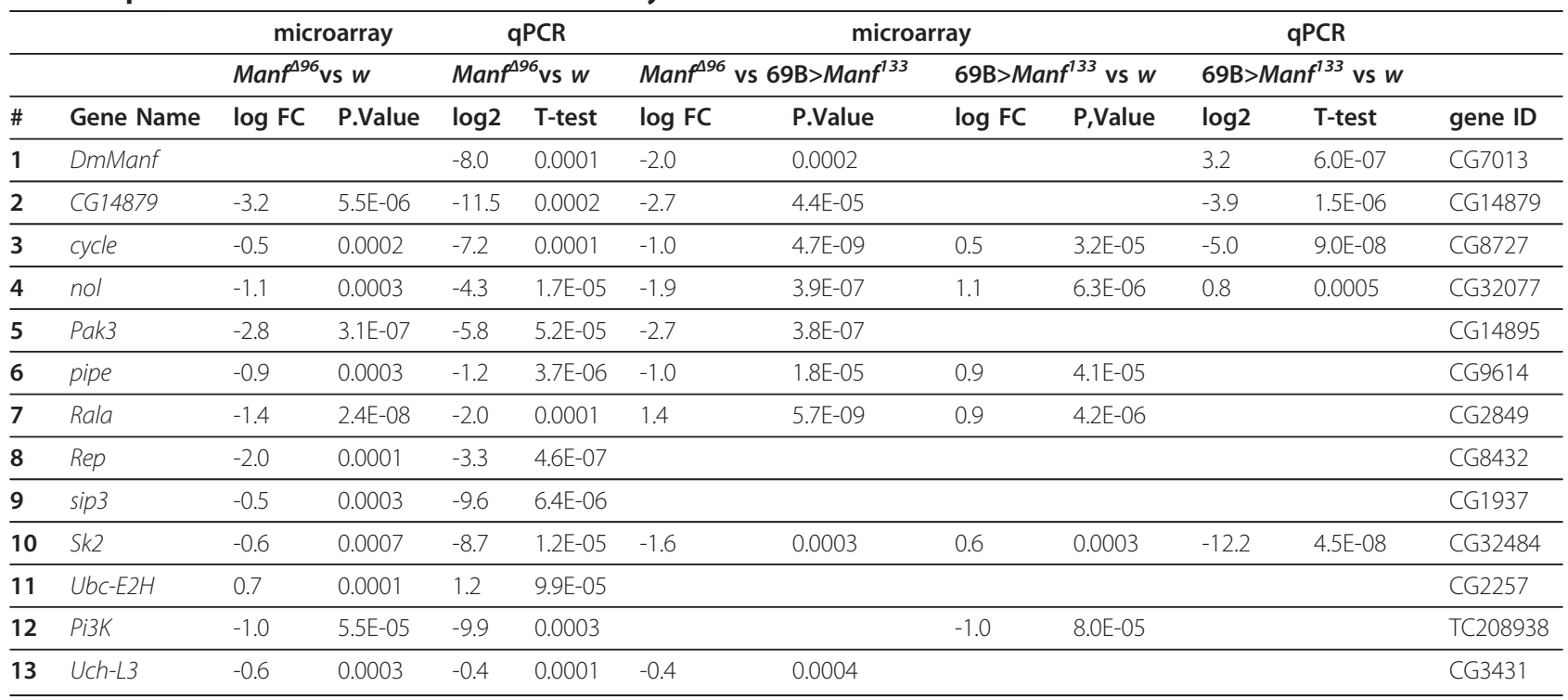

Only statistically significant $(P<0.01)$ results are presented. Results of qPCR results were made comparable to microarray fold change (FC) by calculating the log2 of the relative fold changes. T-test means calculated P-value associated with Student's T-test.

Genes involved in nucleic acid metabolism and protein folding are downregulated in larval Manf $^{\Delta 96}$ mutants Larval Manf ${ }^{496}$ mutants with maternally contributed Manf gene products never reach $3^{\text {rd }}$ instar stage and rarely survive up to 75 hours $\mathrm{AEL}$ at $25^{\circ} \mathrm{C}$. Initially, Manf ${ }^{\Delta 6}$ mutant larvae hatch and feed normally. Whereas wild type larvae grow rapidly, the mutant larvae remain smaller and start to wander away from food, become sluggish and stop moving, still responding to touch and usually die during the first larval molt [5]. Because of the temporal differences in survival between individual Manf ${ }^{\Delta 96}$ mutant larvae from $1^{\text {st }}$ to $2^{\text {nd }}$ instar, for microarray analysis we collected larvae 29-50 hours AEL.
When comparing the expression profile of larval Manf ${ }^{46}$ mutants to the wild type larvae, almost half the number of genes (690) was significantly downregulated as compared to the rate in Manf ${ }^{n z \Delta 96}$ embryos resulting in 140 functional clusters (Additional file 4). The most enriched GO terms fell into clusters related to intracellular organelle lumen and nucleic acid metabolic processes (Table 6). The cellular activities such as DNA replication, RNA processing and splicing were enriched among downregulated genes. The $5^{\text {th }}$ highly enriched cluster consisted of GO terms such as ER related genes (24 genes), proline and arginine metabolism (9 genes), and oxioreductases (9 genes). Mitotic cell cycle, chromosomal

Table 4 GO clustering analysis of downregulated genes in Manf ${ }^{m \Delta 96}$ mutants

\begin{tabular}{lllc}
\hline & GO term & enrichment score & gene number \\
\hline $\mathbf{1}$ & membrane transporters & 2.9 & 25 \\
\hline $\mathbf{2}$ & transmembrane proteins & 2.3 & 146 \\
\hline $\mathbf{3}$ & amine catabolic processes & 2.1 & 11 \\
\hline $\mathbf{4}$ & mitochondrion & 2.0 & 28 \\
\hline$\ldots$ & DNA replication, DNA metabolic process & 1.7 & 26 \\
\hline$\ldots$ & pyrimidine metabolism & 1.5 & 15 \\
\hline$\ldots$ & ncRNA, rRNA metabolic process, ribosome biogenesis & 1.4 & 23 \\
\hline$\ldots$ & structural constituent of chitin-based cuticle & 1.4 & 14 \\
\hline$\ldots$ & Hox, DNA dependent transcription regulation & 1.3 & 122 \\
\hline$\ldots$ & organophosphate, glycerolipid metabolic process & 1.3 & 18 \\
\hline$\ldots$ & neurological system process & 1.0 & 44 \\
\hline
\end{tabular}

Clusters are represented starting from the highest enrichment score in diminishing order. Only the highest clusters are shown, for the full list of DAVID cluster analysis of downregulated genes in Manf ${ }^{m z \Delta 96}$ mutants, see Additional file 2 . In the case of missing order number replaced by "..." there were several clusters higher in order describing similar processes that have been listed already above. 
Table 5 GO clustering analysis of upregulated genes in Manf ${ }^{m z}{ }^{96}$ mutants

\begin{tabular}{lllc}
\hline & GO term & enrichment score & gene number \\
\hline $\mathbf{1}$ & defense response, immune response & 9.4 & 69 \\
\hline $\mathbf{2}$ & endopeptidase activity, proteolysis & 6.4 & 197 \\
\hline$\ldots$ & peptidase inhibitor and enzyme inhibitor activity & 4.0 & 24 \\
\hline$\ldots$ & stress response, response to abiotic stimulus & 3.4 & 31 \\
\hline$\ldots$ & plasma membrane part, integral to plasma membrane & 3.3 & 59 \\
\hline$\ldots$ & actin cytoskeleton organization & 3.1 & 28 \\
\hline$\ldots$ & extracellular region part & 2.8 & 30 \\
\hline$\ldots$ & cell death & 2.7 & 28 \\
\hline$\ldots$ & embryonic and epithelial morphogenesis, cell polarity & 2.5 & \\
\hline$\ldots$ & cell adhesion & 1.7 & \\
\hline$\ldots$ & membrane invagination, phagocytosis, vesicle-mediated transport & 1.6 & 25 \\
\hline
\end{tabular}

Clusters are represented starting from the highest enrichment score in diminishing order. Only the highest clusters are shown, for the full list of DAVID cluster analysis of upregulated genes in Manf ${ }^{m z \Delta 96}$ mutants, see Additional file 3. In the case on missing order number replaced by "..." there were several clusters higher in order describing similar processes that have been listed already above.

segregation, and mitotic spindle organization were also clustered as significantly enriched. These changes could be linked to UPR, as one of the outcomes of UPR is general and unspecific downregulation of novel protein synthesis, at the same time activating the protein synthesis for chaperones and genes enhancing the protein folding to release the unfolded protein load in ER.

Sugar metabolism, hydrolases, and ER related oxidation reduction genes are induced in Manf $^{\Delta 96}$ larvae In Manf ${ }^{966}$ larval mutants, 682 genes showed upregulation in comparison to the wild type larvae. The most enriched functional clusters included GO terms like sugar metabolism and glucosidases, glycosyl hydrolases (18 genes), and hydrolases and carboxylesterases (23 genes), followed by cluster of monooxygenases, Cytochrome $\mathrm{P} 450$, iron, vesicular fraction, oxidation reduction and endoplasmic reticulum (49 genes) (Additional file 5). Chitin and polysaccharide metabolism was also among the highly enriched GO terms (40 genes). The 5 th ranked cluster of GO terms was immune and defence response (19 genes), which was the most highly enriched cluster in Manf ${ }^{n z \Delta 96}$ mutant embryos.

Genes related to RNA metabolism, ATP binding, and DNA replication are downregulated in both Manf mutants

Next, we looked for functional terms among the 208 commonly downregulated genes in both Manf mutants (Additional file 6). There was $30 \%$ of overlap in gene sets between the Manf ${ }^{196}$ and Manf $f^{m \Delta \Delta 6}$ mutants. Among the downregulated overlapping genes, the enrichment of GO terms fell into RNA metabolism and ribosome biogenesis (19 genes). Around 10\% of all known ATP binding genes were downregulated ( 28 genes) together with 14 genes of the purine and pyrimidine metabolism. Additionally, the genes coding sugar transporters and the genes involved in transmembrane transport (7 genes) highly represented among downregulated genes in Manf ${ }^{m z \Delta 96}$ mutant

Table 6 GO clustering analysis of downregulated genes in Manf ${ }^{\Delta 96}$ larval mutants

\begin{tabular}{llll}
\hline & GO term & enrichment score & gene number \\
\hline $\mathbf{1}$ & nuclear lumen, intracellular organelle lumen & 3.9 & 50 \\
\hline $\mathbf{2}$ & ncRNA, rRNA metabolic process & 3.7 & 23 \\
\hline $\mathbf{3}$ & chromosome, non-membrane-bounded organelle & 3.7 & 72 \\
\hline $\mathbf{4}$ & DNA replication, DNA metabolic process & 3.4 & 29 \\
\hline $\mathbf{5}$ & prolyl 4-hydroxylase, oxioreductase, ER part & 3.4 & 24 \\
\hline $\mathbf{6}$ & RNA, mRNA metabolic process, spliceosome & 2.8 & 45 \\
\hline$\ldots$ & mRNA transport, nuclear transport, nuclear export & 1.6 & 14 \\
\hline $\boldsymbol{\ldots}$ & chromosome condensation, DNA packaging & 1.6 & 15 \\
\hline $\boldsymbol{*}$ & cell cycle, mitosis, chromosome segregation & 1.3 & 59 \\
\hline
\end{tabular}

Clusters are represented starting from the highest enrichment score in diminishing order. Only the highest clusters are shown, for the full list of DAVID cluster analysis of downregulated genes in Manf ${ }^{966}$ mutants, see Additional file 4 . In the case on missing order number replaced by "..." there were several clusters higher in order describing similar processes that have been listed already above. 
embryos, were repressed in zygotic mutant $\operatorname{Manf}^{\Delta 96}$ as well. GO terms related to DNA replication (15 genes) were also enriched among the commonly downregulated genes in both Manf mutants.

Altogether, the Manf ${ }^{m z \Delta 96}$ mutant embryos lacking both maternal and zygotic Manf showed twice more drastic decline from wild type transcriptome than Manf ${ }^{\Delta 96}$ larval mutants, whose maternal transcripts gradually diminish. Beside behavioural and growth phenotype, Manf ${ }^{\Delta 96}$ larvae show degeneration of dopaminergic neurites in ventral nerve cord [5]. We found three genes downregulated in both mutants that are involved in neurite development: Abelson tyrosine kinase (Abl), Guanine nucleotide exchange factor GEF64C (Gef64C) and the transcription factor longitudinals lacking (lola).

A third of all upregulated genes (229) were induced in both mutants (Additional file 7). Immune and defense response was the most enriched functional cluster (29 genes) along with the group consisting of monooxygenases, oxidoreductases, vesicular fraction, endoplasmic reticulum, Cytochrome $\mathrm{P} 450$ and lipid metabolic process (21 genes). Controversially, disabled ( $\mathrm{Dab}$, substrate of $A b l$ ), was upregulated among the 10 genes involved in neuronal development e.g. transcription factor Krüppel $(K r)$, negative regulator of growth shrub (shrb), insulin receptor $(\operatorname{InR})$, and Drosophila extracellular-signal-regulated kinase (ERK) rolled $(r l)$.

Genes related to UPR were upregulated in Manf mutants Previous in vitro studies using tunicamycin, the inhibitor of glycosylation, to induce ER stress in mammalian cell lines have shown in UPR the upregulation of MANF $[6,7]$. In rat neonatal cardiomyocytes in response to UPR MANF is secreted to promote cellular survival [8]. ER stress and one of the consequences, UPR, has been mainly studied in yeast and mammalian cells. In Drosophila, there are several recent studies where UPR has been addressed $[16,19]$. Manf has been shown to be upregulated after feeding tunicamycin to adult fruit flies indicating the involvement of Manf in chemically induced UPR in Drosophila [20].

To find out the intracellular localisation of Manf in Drosophila, we used larval $2^{\text {nd }}$ instar garland cells. Garland cells are nephrocytes with high rate of endocytosis and express several neuronal and exocytosis markers e.g. prospero (pros, mammalian Prox-1 homolog), SNARE binding protein Ras opposite (Rop) facilitating neurotransmitter secretion, and Syntaxin $1 A$ (Syx1A, a t-SNARE) [21,22]. These cells have the most abundant expression of Manf starting from embryogenesis [5]. In the garland cells, Manf was localised around the nucleus, partially overlapping with ER-targeted marker (Figure 1A-C).

Next, we tested the hypothesis that the metabolic changes in Manf mutant could be the result of severe
ER stress caused by altered expression of ER related genes. Drosophila genes homologous to several ER stress pathway have been identified. Out of 30 genes involved in ER and protein processing in the KEGG database, 24 have one or more homologues in fruit flies (Figure 2, Table 7). Of these UPR related Drosophila genes, 30\% showed altered gene expression in our microarray experiment. Altogether, 29 genes involved in ER and protein processing show statistically significant expression changes. The gene CG10420 is an annotated gene with unknown function in Drosophila. Its human homologue nucleotide exchange factor SIL1 (S. cerevisiae ER chaperone homologue) is a $\mathrm{BiP}$ binding protein. In humans, several mutations in SIL1 gene disrupting the protein cause the Marinesco-Sjögren syndrome (MSS), an autosomal recessive cerebellar ataxia complicated by cataracts, developmental delay and myopathy [23]. We validated CG10420 by qPCR as downregulated by Manf overexpression and upregulated when Manf is abolished in Drosophila embryos and larvae. It has been shown by immunoprecipitation studies that mammalian MANF binds to BiP [24]. Thus it is possible that Manf and CG10420 compete in binding to BiP together with unfolded proteins. As the ectopic overexpression of Manf has no effect on fruit fly viability or nervous system development (data not shown), the diminished transcript level for CG10420 is not comparable to the total lack of this gene product in the MSS patients. According to our qPCR validated microarray results several other genes implicated in UPR were downregulated in larvae overexpressing Manf, such as pancreatic eIF-2 $\alpha$ kinase (PERK), Heat shock protein 83 (Hsp83), Ubiquilin (Ubqn), and septin interacting protein 3 (sip3). In embryonic Manf $f^{m z 96}$ mutants all above mentioned genes were significantly upregulated as well as considerable number of other ER chaperone genes (Table 7). Furthermore, when evaluating the ultrastructural changes in Manf ${ }^{n z \Delta 96}$ mutants, we noticed that the ER was swollen and dilated in epidermal cells, indicating severe disturbances of ER structure (Figure 3A-C). In Manf ${ }^{m z \Delta 96}$ mutant embryos the extent of phosphorylated eukaryotic initiation factor eIF $2 \alpha$ was more than two fold upregulated when compared to the wild type (Figure 1D) indicating the presence of UPR in these Manf mutants. The phosphorylation of eIF $2 \alpha$ by PERK is a hallmark for UPR, resulting in reversible blockage of translation and downregulation of the protein load to the ER [25]. In Drosophila there are two kinases, PERK and Gcn2, shown to be able to phosphorylate eIF $2 \alpha$ $[26,27]$. The expression of Gcn2 is high only during early stages of embryogenesis [27]. Thus PERK is a potential candidate kinase behind eIF $2 \alpha$ phosphorylation at the end of embryogenesis. Interestingly, our microarray data showed that in Manf ${ }^{m z \Delta 96}$ mutants the 

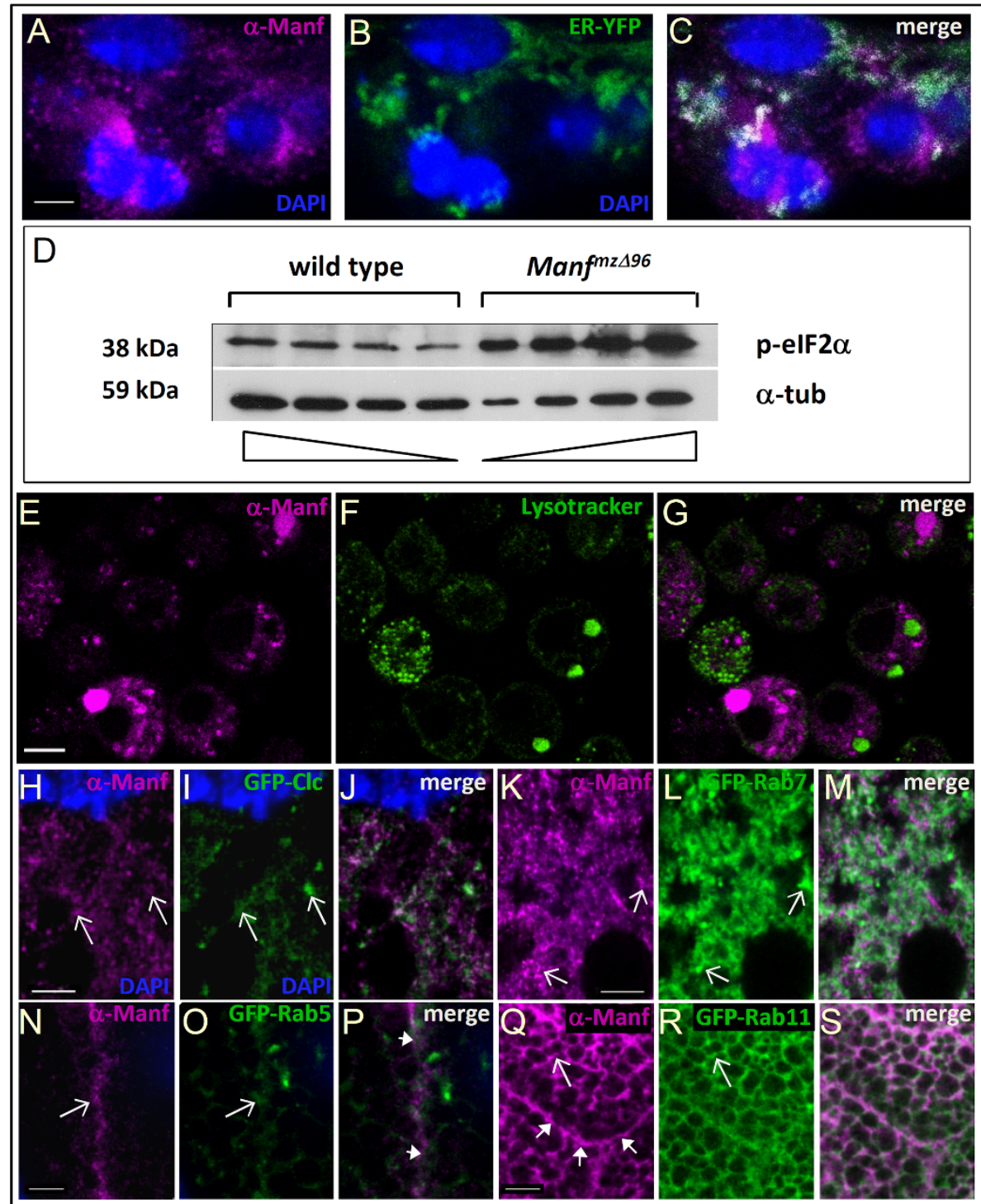

Figure 1 Manf localises intracellularly partially to ER and endosomal compartment. A-C - The confocal micrographs of 2 nd instar larval garland cells stained for $\alpha$-Manf (magenta) showing Manf expression around the nuclei (A) overlapping partially with ER-EYFP marker (green), DAPI (blue) was used to stain nuclei (A-C). D - Western blot analysis shows two fold increased amount of phosphorylated elF2 $\alpha$ in Manf $f^{\text {m } \Delta 96}$ embryos in comparison to wild type $w^{1118}$ embryos. Decreasing amounts of samples were loaded to obtain the optimal result for quantification; the triangles represent the direction of decrease in loading. $\alpha$-tubulin ( $\alpha$-tub) was used as a loading control. E-G - The confocal micrographs of Schneider-2 cells transfected with Manf cDNA construct and stained with Lysotracker (green) and $\alpha$-DmManf show almost no colocalisation (less than $0.3 \%)$. H-M - The confocal micrographs of the wild type 3rd instar larval fat body expressing GFP-tagged UAS-constructs (green) driven by fat body specific ppl-GAL4 and stained for $\alpha$-DmManf (magenta); nuclear stain DAPI (blue) was used. In H-J Manf localises close to clathrin coated vesicles marker GFP-clathrin light chain (Clc). In K-M Manf shows partial colocalisation with late endosomal compartment marker Rab7. N$\mathrm{S}$ - In the salivary gland cells of 3rd instar larvae Manf (magenta) localises close to the basal cell borders and colocalises partially with early endosomal marker Rab5 (green) (N-P) and the recycling endosomal pathway marker Rab11 (green) (Q-S). Close arrows mark the cell borders and the open arrows mark the areas of colocalisation; all images consist of single laser confocal section. Scale bars: in A-C $2 \mu \mathrm{m}, 4 \mu \mathrm{m}$ in $\mathrm{H}-\mathrm{J}, 5 \mu \mathrm{m}$ in $\mathrm{E}-\mathrm{G}$ and $\mathrm{K}-\mathrm{S}$.

transcription of PERK was [25] upregulated and the genes involved in different metabolic processes such as amino acid, DNA and pyrimidine metabolism were downregulated indicating overall inhibition of translation. So it is probable that the UPR PERK pathway is activated in Manf ${ }^{m z \Delta 96}$ mutants. The second UPR sensor, IRE1, activates two separate downstream branches. One of the branches leads to the activation of 


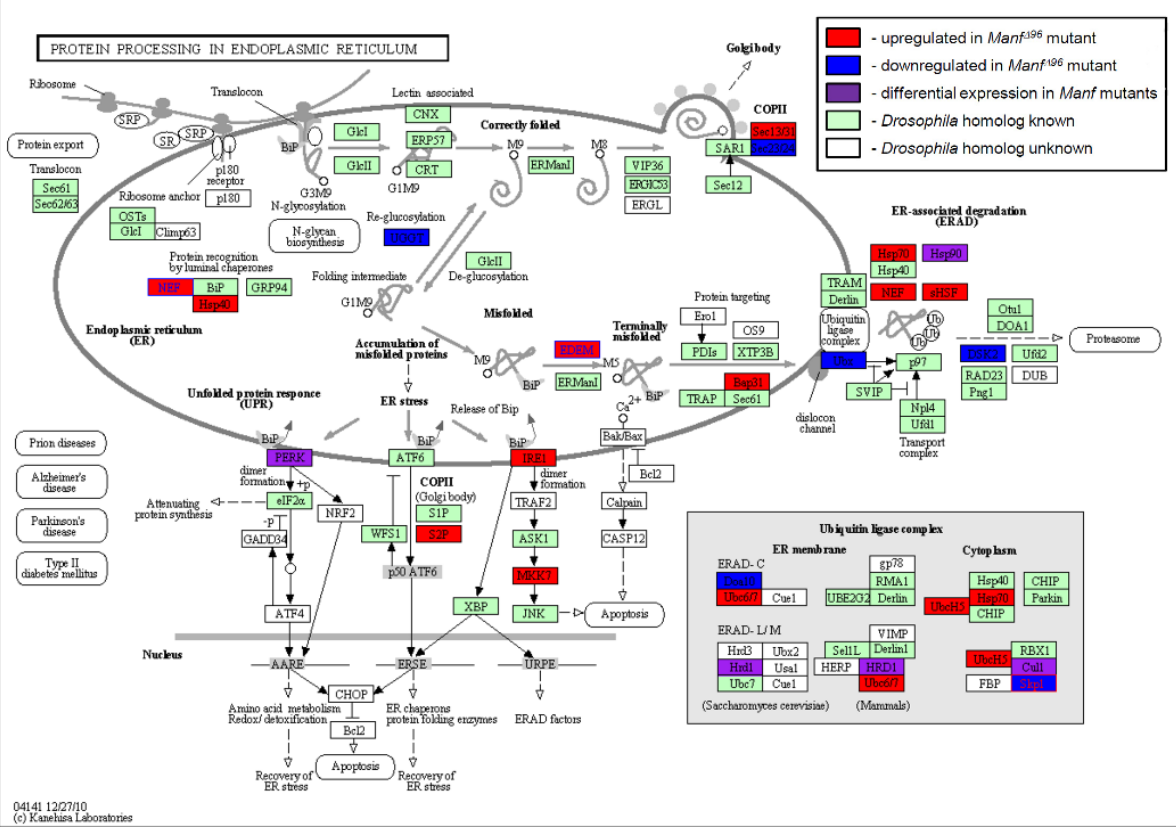

Figure 2 Protein processing in endoplasmic reticulum is altered in Manf mutants. An online coloured KEGG pathway scheme showing altered gene expression in red (upregulation), blue (downregulation), or purple (altered gene expression, differences between the two mutants) boxes. The unaltered known Drosophila homologues to identified components from other organisms are presented in green-filled boxes. The complete list of altered genes is summarised in Table 7. Notice the upregulation of genes encoding BiP/GRP78 chaperone binding proteins and components in ER leading to terminally misfolded protein degradation pathway. Out of the three branches of ER stress, IRE1 pathway leading to cell death shows upregulation in both mutants as PERK pathway is upregulated in maternal and zygotic Manf mutants.

Jun kinase and death pathway [28]. According to the microarray results, Drosophila Jun kinase kinase hemipterous showed significant upregulation in both Manf mutants.

Conclusively, the absolute lack of Manf results in severe ER stress and upregulation of many genes involved in UPR finally leading to the cell death. When maternal Manf stores are gradually decreased in Manf ${ }^{496}$ larvae, there are only few genes upregulated that are related to ER: CG10420, ubiquitin protein ligase $\operatorname{lin} 19$, heat shock protein cognate 1 and ubiquitin-conjugating enzyme CG5823. As our data come mostly from gene expression analyses, further biochemical experiments are needed to identify the exact role of Manf in UPR.

\section{Lack of Manf results in downregulation of several genes in exocytosis pathway}

Ultrastructural study of Manf ${ }^{m z \Delta 96}$ mutants revealed overload of vesicles next to the apical part of epidermal cells and reduced microvillae thought to enhance the capacity of the secretion of these cells (Figure 3C). This result, together with the severe defects observed in the cuticle secretion and organisation (Figure 3B, C), suggested a possible involvement of the genes of the exocytosis pathway. Indeed, the expression of several genes related to exocytosis and SNARE transport were altered in different Manf conditions (Table 8 Additional file 8). In Manf mutants, several genes implied in exocytosis and vesicle transport from Golgi complex to the plasma membrane were downregulated (Syx1A, Syx6, SNAP29), whereas the ER residing syntaxins - Stx 17 and Stx 18 - were upregulated. This supports an inhibition of secretion from Golgi complex to the plasma membrane as seen in Manf ${ }^{n z \Delta 96}$ mutant epidermal cells in vesicle accumulation close to the apical area (Figure 3C).

\section{Expression of genes involved in cuticle development were altered in Manf ${ }^{m z \Delta 96}$ mutants}

We have previously shown that Manf ${ }^{m z \Delta 96}$ embryos have disorganized cuticle [5]. At the end of embryogenesis from stage 16 onward, the cuticle components are secreted by epithelial cells and stored in regular layers, and subsequently the cuticular proteins are crosslinked by dopamine-derived quinones [29,30]. Among the downregulated genes in Manf $f^{n z \Delta 96}$ embryos, there were 14 genes coding the structural components of the insect cuticle. At the same time, several other genes responsible for cuticle development were upregulated, such as the genes encoding enzymes involved in chitin synthesis, krotzkopf verkehrt (kkv, chitin synthase-1) [31,32], knickkopf (knk, N-glycosylated membrane-bound extracellular protein involved in chitin microfibril formation) [33], and 
Table 7 List of genes with altered expression according to microarray analysis related to KEGG pathway of protein processing in ER

\begin{tabular}{|c|c|c|c|c|c|c|}
\hline KEGG & & & oryo & & larvae & \\
\hline name & gene & o.ex. & mut. & o.ex. & mut . & description \\
\hline NEF & CG10420 & down & up & down & up & SIL1, BiP-associated protein, mutated in MSS \\
\hline Hsp90 & hsp83 & & up & down & down & Heat shock protein 83 \\
\hline PERK & pek & & up & down & down & PEK; pancreatic elF-2alpha kinase, UPR sensor \\
\hline Hrd1 & $\operatorname{sip} 3$ & & up & down & down & septin interacting protein 3 , ERAD \\
\hline DSK2 & ubian & & up & down & down & ubiquilin, ubiquitin-ass./transl. elongation factor EF1B \\
\hline Cul1 & $\operatorname{lin} 19$ & & down & up & up & lin-19-like, ubiquitin protein ligase, cullin homology \\
\hline Skp1 & $s k p C$ & & down & up & down & skpC, E3 ubiquitin ligase \\
\hline EDEM & Edem 1 & & & up & down & Edem1, Glycoside hydrolase \\
\hline Ubx & $p 47$ & & & down & down & p47, human NSFL1 \\
\hline Skp1 & skpE & & down & & down & RNA polymerase II transcription elongation factor \\
\hline $\operatorname{Sec} 23 / 24$ & CG1472 & down & & & down & COP complex II, mediator of selective export from ER \\
\hline UGGT & CG6850 & & & & down & UDP-glucose-glycoprotein glucosyltransferase \\
\hline $\mathrm{DOA} 10$ & CG1317 & & down & & & E3 ubiquitin-protein ligase MARCH6 \\
\hline $\operatorname{Sec} 13 / 31$ & CG6773 & & up & up & up & involved in export from ER, nuclear import, cuticle development \\
\hline MKK7 & CG4353 & & up & & up & hemipterous, Jun kinase kinase \\
\hline Hsp70 & $\mathrm{Hspcl}$ & & & & up & Heat shock protein cognate 1 \\
\hline $\mathrm{Ubc6/7}$ & CG5823 & & & & up & ubiquitin-conjugating enzyme E2 J2 \\
\hline $\mathrm{Hsp} 40$ & dnajh & & up & & & DnaJ homolog subfamily B member 11 \\
\hline NEF & CG10973 & & up & & & hsp70-interacting protein \\
\hline Bap31 & CG13887 & & up & & & B-cell receptor-associated protein 31 \\
\hline NEF & CG2918 & & up & & & hypoxia up-regulated 1 \\
\hline sHSF & I(2)efl & & up & & & lethal (2) essential for life \\
\hline IRE-1 & ire-1 & & up & & & inositol requiring enzyme 1, Ser/Thr kinase, UPR sensor \\
\hline Hsp70 & Hsp68 & & up & & & Heat shock protein 68 \\
\hline $\mathrm{UbcH} 5$ & Ubce2 & & up & & & Ubiquitin conjugating enzyme 2 \\
\hline Hsp70 & Hspc2 & & up & & & Heat shock protein cognate 2 \\
\hline NEF & CG7945 & & up & & & BCL2-associated athanogene 2 \\
\hline Sec13/31 & CG8266 & & up & & & COP II complex, secretory vesicle budding from ER \\
\hline$\overline{S 2 P}$ & S2P & & up & & & endopeptidase \\
\hline
\end{tabular}

Significant alterations in gene expression from wild type are shown by word code; "up" represents upregulation and "down" downregulation of gene expression. Gene name stands for the particular homologue gene name in Drosophila. Notice that the same KEGG identifier can lead to several different genes. p.res = paternal rescue, mut $=$ mutant, o.ex. $=$ overexpression.

Syx $1 A$ (responsible for cuticle component secretion). Additionally, several genes involved in epithelial development and morphogenesis were upregulated and significantly enriched among the GO terms (35 genes) (Table 5 and Additional file 3).

We used transmission electron microscopy (TEM) analysis in Manf ${ }^{n z \Delta 96}$ mutants at the embryonic stage 17 to investigate the epithelial cells responsible for cuticle secretion. Indeed, these cells showed morphologically abnormal ER and accumulation of vesicles in the apical part (Figure $3 \mathrm{~A}-\mathrm{C}$ ). It is possible that the enhanced endocytosis and disturbed exocytosis, together with misbalance in cuticular components, lead to disorganised and disrupted cuticle in Manf ${ }^{m z \Delta 96}$ mutant embryos. In larval Manf ${ }^{\Delta 96}$ mutant with gradually fading maternal contribution, the cuticle showed no disruption and the chitin layers were deposited and organised normally (Figure 3D, E). Instead there were problems in shedding the old cuticle and often the $1^{\text {st }}$ instar cuticle remained attached (Figure 3E). This implies that the maternal loading of Manf gene products in larval Manf ${ }^{\Delta 96}$ mutants was sufficient to overcome defects in early cuticle development, secretion and layering, but insufficient to complete the first molt.

\section{Large vesicles filled with electron dense debris are accumulated in Manf ${ }^{m \Delta 96}$ mutant}

To investigate the routes of membrane trafficking we evaluated genes involved in endocytosis. Of all Drosophila 


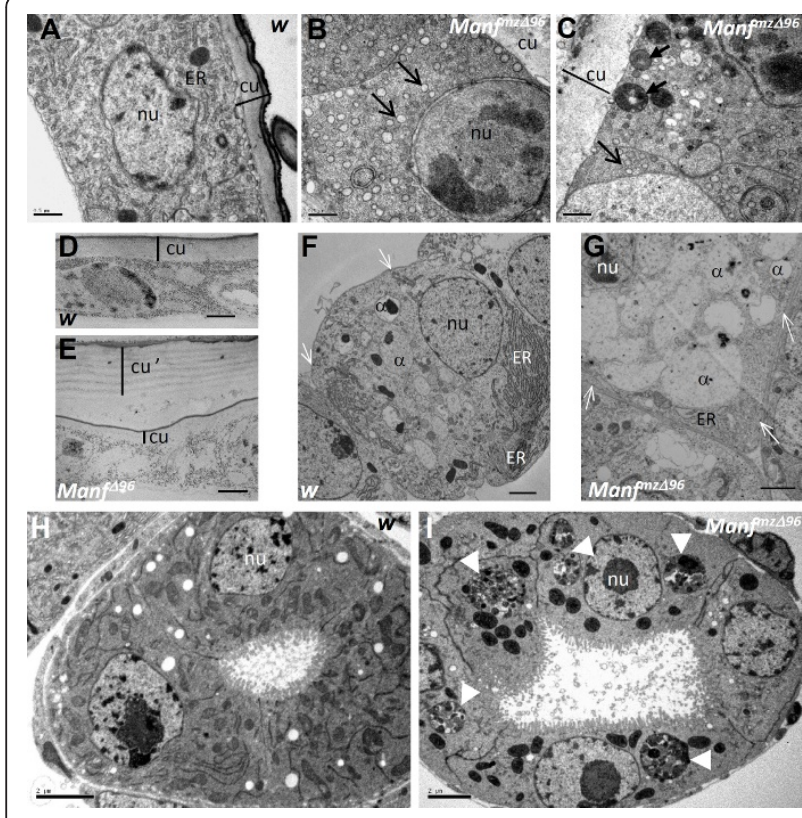

Figure 3 Manf mutants show severe defects in vesicular traffic in the cells with high secretion or endocytosis rate. A-C - In the epidermal cells of stage 17 Manf $^{m z \Delta 96}$ mutant embryos compared to wild type (w), ER is rounded and swollen (open arrow), there are multiple vesicles stuck close to plasma membrane (thick arrow), and the cuticle (cu) is severely disorganized. Cuticular layers are indicated by a line. $n u=$ nucleus D-E - High pressure freezing TEM images of 1st-2nd instar larvae show no difference in the layering of the cuticle between wild type and Manf $f^{196}$ mutant. The cellular membranes are weakly stained by this technique. Notice the unattached first instar cuticle in Manf $f^{196}$ mutant ( $\mathrm{cu}^{\prime}$ in E). F-G The comparison of wild type and Manf $f^{196}$ mutant garland cells shows excessive accumulation and enlargement of $\alpha$-vesicles $(\alpha)$ and dilated ER. The labyrinth channels and slit membranes are similar between wild type and Manf ${ }^{m z \Delta 96}$ mutant (white open arrows). $\mathrm{H}-\mathrm{I}$ Secretory cells of gastric caeca in Manf ${ }^{\text {nz } \triangle 96}$ mutant show accumulation of vesicles full of debris (white arrow heads) never found in wild type. Scale bars: in A-E $500 \mathrm{~nm}, 1 \mu \mathrm{m}$ in F and G, 2 $\mu \mathrm{m}$ in $\mathrm{H}$ and $\mathrm{I}$.

homologues known to be involved in endocytosis, $47 \%$ showed significant expression changes in our microarray experiment (Figure 4, Table 9). Genes coding for components of multivesicular body formation were especially altered. Several transmembrane receptors of growth factors were downregulated in Manf mutants and upregulated when Manf was overexpressed. PDGF- and VEGFreceptor related $P v r$ was upregulated in larvae in both lack and overexpression of Manf. Cbl, an E3 ubiquitin ligase and negative regulator of tyrosine kinase receptor signalling, was downregulated in mutant larvae and upregulated under Manf overexpression conditions. Two different members of endosomal recycling pathway, PAR family members and Rab-protein 11 (Rab11) were upregulated in mutants. PAR transcripts were upregulated by Manf overexpression as well.
To visualise Manf expression at subcellular level we used $3^{\text {rd }}$ instar larval salivary gland cells that are the largest ones found in Drosophila. In the basal part, there was partial colocalisation of Manf expression with GFPRab11 (Figure 1Q-S) as well as with early endosomal marker GFP-Rab5 (Figure 1N-P). In larval fat body large cells with high secretory capacity GFP-clathrin light chain (Clc), a marker for clathrin coated vesicles, colocalised with Manf in some structures (Figure $1 \mathrm{H}-\mathrm{J}$ ). Manf localised close to GFP-Rab7, an important player in trafficking between the early and late endosomes and lysosomes, showing weak colocalisation (Figure 1L-N). Thus Manf localises to the endosomal structures with markers Clc, Rab5, Rab7, and Rab11; but probably does not share the same protein complexes with them.

Ultrastructural analysis of Manf ${ }^{m z \Delta 96}$ mutant stage 17 embryos revealed that the cells of secretory tissues such as gastric caeca, contain huge vesicles filled with cellular debris resembling multivesicular bodies and autophagosomes (Figure 3I). These structures were clearly missing in wild type embryos of the same age (Figure $3 \mathrm{H}$ ). It is possible that these vesicles contain the misfolded proteins to be degraded or, alternatively, that the autophagy pathway is activated. The accumulation of vesicles full of debris to be degraded could be also due to the blockage in endosomal trafficking or lysosomal degradation.

\section{Lysosomal genes are downregulated in Manf mutants}

Because we detected in secretory cells the accumulation of multivesicular body like structures, is it possible that the lysosomal digestion mechanism was altered. Our microarray analysis revealed transcriptional change in $45 \%$ of lysosome related genes present in the KEGG database. Many of them were downregulated in Manf ${ }^{n z \Delta 96}$ embryos and some in Manf ${ }^{496}$ larvae (Table 10; Additional file 9). The ATPase $\mathrm{V}$-type $\mathrm{H}^{+}$transporting subunit that maintains acidic environment in lysosomes showed downregulation in both mutants but was upregulated in Manf overexpressing larvae. The expression of other lysosomal membrane proteins and several lysosomal hydrolases was also altered.

At the subcellular level, Manf colocalises partially with ER-targeted marker and very poorly if not at all with the lysosomal compartment (Figure 1F-H). Nonetheless, it is possible that the lack of Manf modifies the fusion of lysosomes with multivesicular body-like structures by some still unidentified mechanism.

\section{Paternal rescue of the Manf ${ }^{m z \Delta 96}$ mutant embryos leads to reduction in the amount of differentially expressed genes}

In Drosophila, substantial bulk of transcribed mRNAs and translated proteins necessary for early embryonic patterning and development are maternally contributed 
Table 8 List of genes with altered expression according to microarray analysis related to KEGG pathway of exocytosis and SNARE complexes

\begin{tabular}{|c|c|c|c|c|c|c|}
\hline \multirow{2}{*}{$\begin{array}{l}\text { KEGG } \\
\text { name }\end{array}$} & \multirow[b]{2}{*}{ gene } & \multicolumn{2}{|c|}{ embryo } & \multicolumn{2}{|r|}{ larvae } & \multirow[b]{2}{*}{ description } \\
\hline & & o.ex. & mut. & o.ex. & mut. & \\
\hline Bos & CG4780 & up & up & up & down & membrin \\
\hline Vti1 & koko & & & up & down & kokopelli; cyclin-dependent protein kinase regulator \\
\hline SNAP29 & usnp & up & down & & down & usnp; ubisnap \\
\hline \multirow[t]{2}{*}{ Stx6 } & Syx 6 & up & down & & & Syntaxin 6 \\
\hline & Syt7 & & down & down & down & calcium-dependent phospholipid binding, Synaptotagmin. \\
\hline Stx1-4 & Syx $1 A$ & & & down & down & Syntaxin $1 \mathrm{~A}$ \\
\hline \multirow[t]{2}{*}{ Stx17 } & Syx 17 & & & down & up & synaptic vesicle docking; neurotransmitter secretion \\
\hline & Synd & & up & & up & neurotransmitter secretion; synaptic vesicle endocytosis \\
\hline \multirow[t]{2}{*}{ Stx13 } & Syx 13 & & up & & & SNAP receptor: cytokinesis after mitosis and meiosis \\
\hline & Syb & up & up & & & SNAP receptor: synaptic vesicle docking in exocytosis \\
\hline Syx18 & Syx 18 & up & up & & & Syntaxin 18 \\
\hline Bet1 & CG14084 & up & up & & & Bet1 \\
\hline VAMP7 & CG1599 & up & up & & & vesicle-associated membrane protein 7 \\
\hline
\end{tabular}

Significant alterations in gene expression from wild type are shown by word code; "up" represents upregulation and "down" downregulation of gene expression. Gene name stands for the particular homologue gene name in Drosophila. Few related Drosophila genes associated with neurotransmission missing from KEGG pathway were added. The according coloured scheme for exocytosis and SNARE of KEGG pathway is presented in Additional File 8. p.res = paternal rescue, mut = mutant, o.ex. = overexpression.

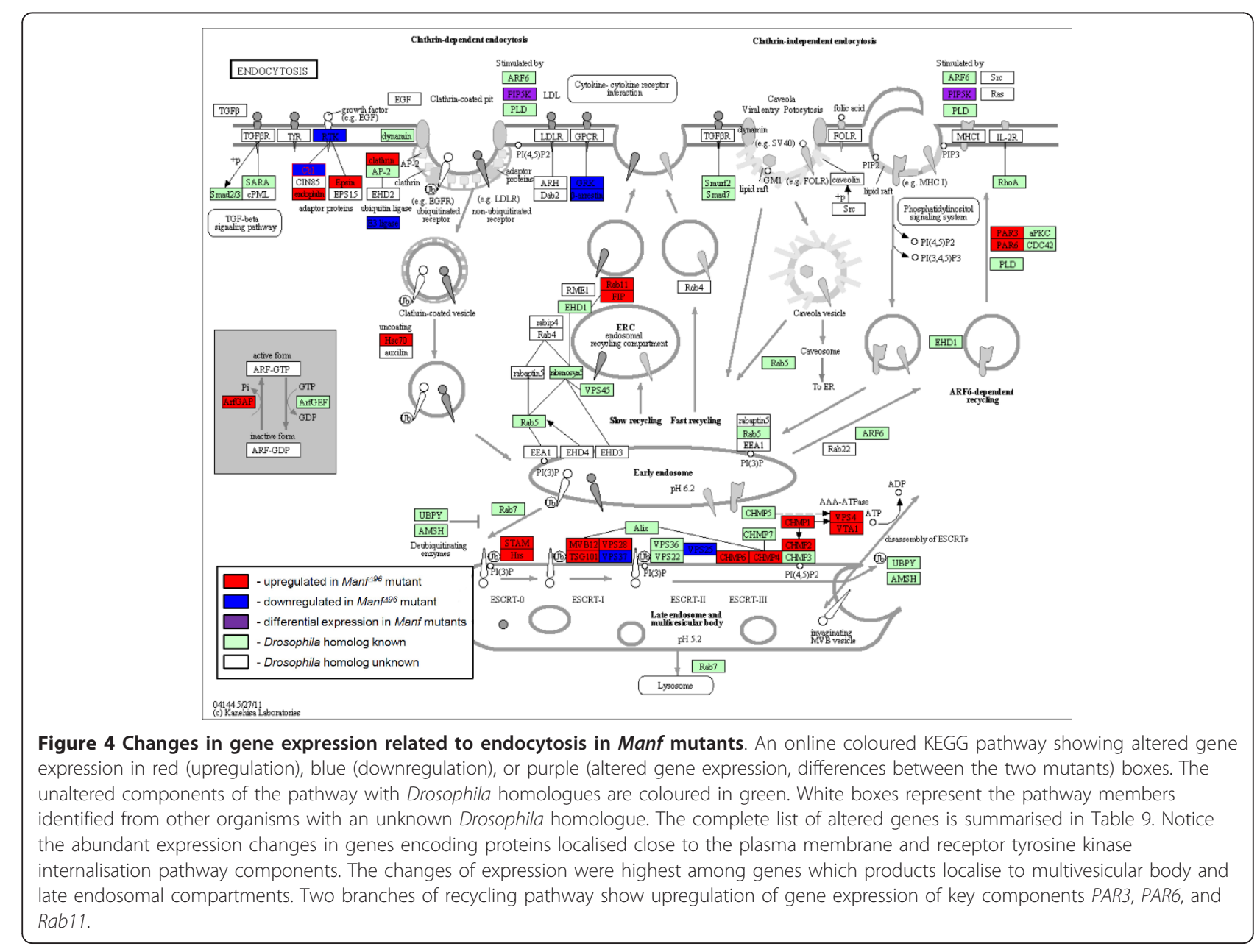


Table 9 List of genes with altered expression according to microarray analysis related to endocytosis KEGG pathway

\begin{tabular}{|c|c|c|c|c|c|c|}
\hline \multirow{2}{*}{$\begin{array}{l}\text { KEGG } \\
\text { name }\end{array}$} & \multirow{2}{*}{$\begin{array}{l}\text { Gene } \\
\text { name }\end{array}$} & \multicolumn{2}{|c|}{ embryo } & \multicolumn{2}{|c|}{ larvae } & \multirow[b]{2}{*}{ description } \\
\hline & & o.ex. & mut. & o.ex. & mut. & \\
\hline RTK & $h+1$ & & & & down & Fgf receptor \\
\hline RTK & EGFR & & & up & down & Egf receptor \\
\hline ArfGAP & GAP69C & & down & up & down & GTPase-activating protein $69 \mathrm{C}$ \\
\hline VPS25 & VPS25 & & & & down & Vacuolar protein sorting 25 \\
\hline beta-arrestin & $k r z$ & & & up & down & kurtz, $\beta$-arrestin \\
\hline E3 ligase & Traf6 & up & down & & down & TNF-receptor-associated factor 6 \\
\hline E3 ligase & elgi & up & down & & & early girl \\
\hline GRK & GPCRK 1 & up & down & & & G protein-coupled receptor kinase 1 \\
\hline RTK & $\operatorname{Ret}$ & up & down & & & Ret oncogene \\
\hline Cbl; E3 ligase & $\mathrm{Cbl}$ & up & up & up & down & ubiquitin mediated proteolysis \\
\hline VPS37 & CG11155 & up & down & down & & ESCRT-I complex subunit VPS37 \\
\hline PIP5K & CG17471 & up & down & down & up & 1-phosphatidylinositol-4-phosphate 5-kinase \\
\hline CHMP4 & shrb & down & up & down & up & shrub, charged multivesicular protein \\
\hline $\mathrm{Hsc70}$ & Hspc 2 & & up & down & up & Heat shock protein cognate 2 \\
\hline FIP & nuf & down & up & down & up & nuclear fallout, Rab11 interacting protein \\
\hline Epsin & Ifs & & up & down & up & liquid facets \\
\hline endophilin & endo $B$ & & & down & up & endophilin B \\
\hline CHMP6 & Vps20 & down & up & & & vacuolar protein sorting 20 \\
\hline Clathrin & Che & down & up & & & Clathrin heavy chain \\
\hline TSG101 & TSG101 & down & up & & & tumor suppressor protein 101 \\
\hline STAM & Stam & & & & up & signal transducing adaptor molecule \\
\hline VPS28 & Vps28 & & up & & up & vacuolar protein sorting 28 \\
\hline PAR6 & par-6 & & up & up & up & partitioning defective 6 \\
\hline $\mathrm{Hsc70}$ & Hspc 1 & & & up & up & Heat shock protein cognate 1 \\
\hline $\mathrm{Hsc70}$ & Hsp 68 & up & up & & & Heat shock protein 68 \\
\hline RTK & Pvr & up & up & & & PDGF- and VEGF-receptor related \\
\hline ARFGTPase & CG7435 & up & up & & & ADP ribosylation factor $84 \mathrm{~F}$ \\
\hline ArfGAP & CG30372 & up & up & & & SH3 domain, ANK repeat and PH domain \\
\hline ArfGAP & $\operatorname{cen} B 1 A$ & up & up & & & centaurin beta $1 \mathrm{~A}$ \\
\hline VPS4 & Vps4 & up & up & & & vacuolar protein sorting 4 \\
\hline CHMP2 & CG14542 & up & up & & & charged multivesicular body protein $2 \mathrm{~A}$ \\
\hline CHMP2 & CG4618 & up & up & & & charged multivesicular body protein $2 \mathrm{~B}$ \\
\hline MVB12 & CG7192 & up & up & & & ESCRT-I complex subunit MVB12 \\
\hline Hrs & Hrs & up & up & & & HGF regulated tyrosine kinase substrate \\
\hline PAR3 & baz & up & up & & & bazooka, partitioning defective 3 \\
\hline VTA1 & CG7967 & up & up & & & vacuolar protein sorting-associated protein \\
\hline CHMP5 & CG6259 & & up & & & charged multivesicular body protein 5 \\
\hline CHMP1 & CG4108 & & up & & & charged multivesicular body protein 1 \\
\hline ArfGAP & cenGIA & & up & & & centaurin gamma $1 \mathrm{~A}$ \\
\hline Rab11 & Rab 11 & & up & & & Rab-protein 11 \\
\hline
\end{tabular}

Significant alterations in gene expression from wild type are shown by word code; "up" represents upregulation and "down" downregulation of gene expression. Gene name stands for the particular homologue gene name in Drosophila. Notice that the same KEGG identifier can lead to several different genes in Drosophila. The according coloured scheme for endocytosis KEGG pathway is presented in Figure 4.

to the oocyte at high levels. These mRNAs and proteins are stored and used gradually during the embryogenesis and in some cases through the whole larval development.
When the embryonic lack of maternal Manf was rescued by paternal wild type gene expression, the transcriptome changes were evident but restricted to a smaller number 
Table 10 List of genes with altered expression according to microarray analysis related to KEGG lysosome pathway

\begin{tabular}{|c|c|c|c|c|c|c|}
\hline \multirow{2}{*}{$\begin{array}{l}\text { KEGG } \\
\text { name }\end{array}$} & \multirow{2}{*}{$\begin{array}{l}\text { Gene } \\
\text { name }\end{array}$} & \multicolumn{2}{|c|}{ embryo } & \multicolumn{2}{|c|}{ larvae } & \multirow[b]{2}{*}{ Description } \\
\hline & & o.ex. & mut. & o.ex. & mut. & \\
\hline$\overline{A G A}$ & CG10474 & & down & & down & N4-(beta-N-acetylglucosaminyl)-L-asparaginase \\
\hline $\mathrm{SGSH}$ & CG14291 & & & up & down & N-sulfoglucosamine sulfohydrolase \\
\hline$\overline{A P-3}$ & $\mathrm{~cm}$ & & & up & down & carmine \\
\hline ARS & CG7402 & & down & down & down & arylsulfatase $\mathrm{B}$ \\
\hline ATPeV & CG7678 & & down & up & down & V-type H+-transporting ATPase subunit I \\
\hline ATPeV & Vha100-1 & up & down & & & Vha100-1 \\
\hline ATPeV & VhaSFD & & down & & & Vacuolar H[+]-ATPase SFD subunit \\
\hline cystinosin & CG17119 & up & down & & & cystinosin \\
\hline$\overline{\text { GUSB }}$ & CG2135 & up & down & & & beta-glucuronidase \\
\hline cathepsin & cathD & & down & & & cathepsin D, pepsin A \\
\hline LAMAN & CG6206 & up & down & & & lysosomal alpha-mannosidase \\
\hline CLN3 & $\ln 3$ & & down & & & $\operatorname{cln} 3$ \\
\hline GLA & CG7997 & & down & & & alpha-galactosidase \\
\hline ATPeV & Vha16 & & & down & up & Vacuolar H[+] ATPase $16 \mathrm{kD}$ subunit \\
\hline LYPLA3 & CG31683 & & down & down & up & lysophospholipase III \\
\hline$\overline{\mathrm{CLN} 1}$ & Ppt2 & up & down & down & up & Palmitoyl-protein thioesterase 2 \\
\hline LAMAN & CG5322 & up & down & down & up & lysosomal alpha-mannosidase \\
\hline$\overline{L Y M P}$ & trpml & & down & down & up & control of membrane trafficking of proteins and lipids \\
\hline NAGA & CG5731 & up & down & up & up & alpha-N-acetylgalactosaminidase \\
\hline LIMP & Tsp39D & & & down & up & Tetraspanin 39D \\
\hline LIMP & Tsp29Fa & & & down & up & Tetraspanin 29Fa \\
\hline HGSNAT & CG6903 & & & down & up & heparan-alpha-glucosaminide $\mathrm{N}$-acetyltransferase \\
\hline saposin & Sap-r & & & down & up & Saposin-related \\
\hline cathepsin & cathF & & & down & up & cathepsin F \\
\hline LAMAN & CG9466 & & & down & up & lysosomal alpha-mannosidase \\
\hline LAMAN & CG9463 & & & down & up & lysosomal alpha-mannosidase \\
\hline$\overline{A P-3}$ & $g$ & down & up & & & garnet, adaptor-related protein complex 3 \\
\hline clathrin & Che & down & up & & & Clathrin heavy chain \\
\hline$\overline{G L B}$ & CG9092 & up & up & up & up & beta galactosidase \\
\hline GTPase & Gie & & & & up & N-terminally acetylated Arf-like GTPase \\
\hline LAMAN & CG9465 & & & & up & lysosomal alpha-mannosidase \\
\hline$\overline{\mathrm{GBA}}$ & CG31148 & up & up & & up & glucosylceramidase \\
\hline cathepsin & cathL & up & up & & & cathepsin $\mathrm{L}$ \\
\hline GNS & CG18278 & up & up & & & $\mathrm{N}$-acetylglucosamine-6-sulfatase \\
\hline$\overline{\mathrm{GGA}}$ & Gga & up & up & & & Gga \\
\hline $\mathrm{AP}-1$ & $A P-1 \mathrm{~s}$ & up & up & & & AP-1sigma \\
\hline cathepsin & $C p 1$ & up & up & & & Cysteine proteinase-1 \\
\hline LYMP & spin & up & up & & & spinster, lysosomal turnover regulator \\
\hline$\overline{\text { GNS }}$ & CG30059 & & & up & & $\mathrm{N}$-acetylglucosamine-6-sulfatase \\
\hline
\end{tabular}

Significant alterations in gene expression from wild type are shown by word code; "up" represents upregulation and "down" downregulation of gene expression. ID stands for the particular homologue gene name in Drosophila. Notice that the same KEGG identifier can lead to several different genes. The according coloured scheme for lysosome KEGG pathway is presented in Additional File 9.

of genes than changes caused by the complete lack of Manf. As many as 98 genes were significantly upregulated by paternal rescue resulting in 18 functionally enriched GO term clusters (Additional file 10). We obtained GO terms related to response to stimulus and neurological process (8 genes), consisting of genes like transcription factor pros, pumilio (pum; encoding a mRNA binding protein involved in nervous system 
development), pastrel (pst; with unknown molecular function involved in memory and learning), Rop, $r l$, and small optic lobes (sol; calpain family peptidase). Transcripts of several genes coding membrane proteins also showed enrichment. Among them, we observed many genes coding ion-binding proteins (19\%) such as klumpfuss $(k l u)$ and odd skipped (odd; DNA binding Zn-finger proteins important for embryonic nervous system development). Other enriched GO term clusters were membrane (7 genes) together with cell division, cell cycle and cytoplasm (9 genes).

Only 34 genes were downregulated by paternal rescue giving 4 functional GO term clusters (Additional file 11).

\section{Ubiquitous overexpression of Manf results in transcriptional activation and upregulation of genes involved in cell cycle and cell death}

We used enhancer trap line 69B-GAL4 to overexpress Manf, which we obtained as a commonly known GAL4 line with an epidermal expression pattern. After careful mapping the expression pattern of $69 B-G A L 4$, we detected broad GAL4 expression in other tissues than epidermis - in central nervous system (non-glial), imaginal discs (wing and eye-antennal disc), garland cells, ring gland, but neither in fat body nor in gastric caeca. Ectopic expression of Manf under 69B-GAL4 rescues completely Manf ${ }^{\Delta 96}$ mutant lethality and the rescued adults are viable and fertile if maintained as a stock [5].

When comparing the gene expression profiles between Manf overexpressing and wild type larvae we found 614 genes upregulated that could be grouped in 102 functional GO term clusters (Additional file 12). This gene set showed enrichment in processes related to regulation of gene expression, protein localisation and transport, and cell cycle (e.g. kokopelli, an uncharacterized cyclin involved in stem cell maintenance and Retinoblastoma-family protein, the human $R b$ homolog). Genes involved in regulation of cell death were also upregulated (e.g. CG7188, a putative Bax inhibitor, $r l$, and $k l u$ ). According to the previous study in HeLa cells, knockdown of MANF increased cell proliferation and susceptibility to ER stress induced cell death [7]. Our results support the involvement of Manf in regulation of cell cycle and cell death offering several candidate genes for further studies.

Manf overexpression in larvae caused downregulation of 340 genes annotated in 78 functional clusters (Additional file 13). The most prominent group consisted of GO terms such as membrane, plasma membrane, signal peptide, glycoprotein, disulfide bond, glycosylation site: Nlinked (GlcNAc), integral to membrane, and transmembrane (77 genes). The majority of processes related to these GO terms take place in the ER such as cleavage of the signal peptide and disulfide bond formation. The main arthropod cuticular component chitin is composed of polymerised GlcNAc residues. Another prominent group was ion binding and metal binding (70 genes). Axon guidance, cell projection organization, neuron development, axonal defasciculation, cell motion, cell recognition $(20$ genes) were also enriched in line with our previous results implicating the role of Manf in neuritogenesis [5].

When comparing the upregulated genes in both paternally rescued embryos and in Manf overexpressing larvae, the common represented GO term clusters were ion binding (14 genes), membrane fraction (7 genes), oxidation reduction ( 8 genes) and cell cycle ( 5 genes) (Additional file 14). All together there were 57 annotated genes commonly upregulated by Manf, among these well known genes like $\mathrm{Cbl}$, diaphanous (dia, formin, essential for actin-mediated events involving membrane invagination), Kinesin-like protein at 68D (Klp68D), rl, and Rop. Among the downregulated genes in both paternal rescue and Manf overexpression, there were only 6 genes in common e.g. CG34384, a diacylglycerol kinase involved in phosphoinositol signalling and glycerolipid metabolism. Conclusively, in Manf overexpression the typical growth factor signalling mediators $r l$ and $C b l$ were upregulated. The links upstream of these mediators and downstream of secreted Manf still remain missing. The second cluster of genes was directly linked to membrane modifications and transport. Interestingly, the intracellular protein modification processes in ER were also enhanced by Manf overexpression. So presumably Manf has a dual role - one intracellularily in the ER, and the other extracellularly after being secreted.

\section{Differentially regulated genes in larval Manf $^{\mathrm{A96}}$ mutant in comparison to Manf overexpression}

Next, we searched for genes showing downregulation in Manf ${ }^{496}$ larval mutant and were upregulated in Manf overexpression condition, and vice versa. Altogether 89 probes on the microarray showed this opposite regulation resulting in 62 annotated Drosophila genes (Additional file 15). In this group, there were genes responsible for locomotory behaviour ( 3 genes), genes involved in oxidation reduction and metal binding (10 genes), in cell division (4 genes), genes coding membrane proteins (7 genes), and genes involved in insulin signalling (2 genes). Because of the diversity of GO terms and low number of genes the functional annotation clustering did not give statistically significant results.

\section{UPR and Parkinson's disease}

Among the known genes involved in PD, 32 are conserved between mammals and Drosophila, and $44 \%$ of these were differentially expressed in our microarray assay (Figure 5, Table 11). Importantly, several genes from dopamine uptake (Dopamine transporter, DAT) and 


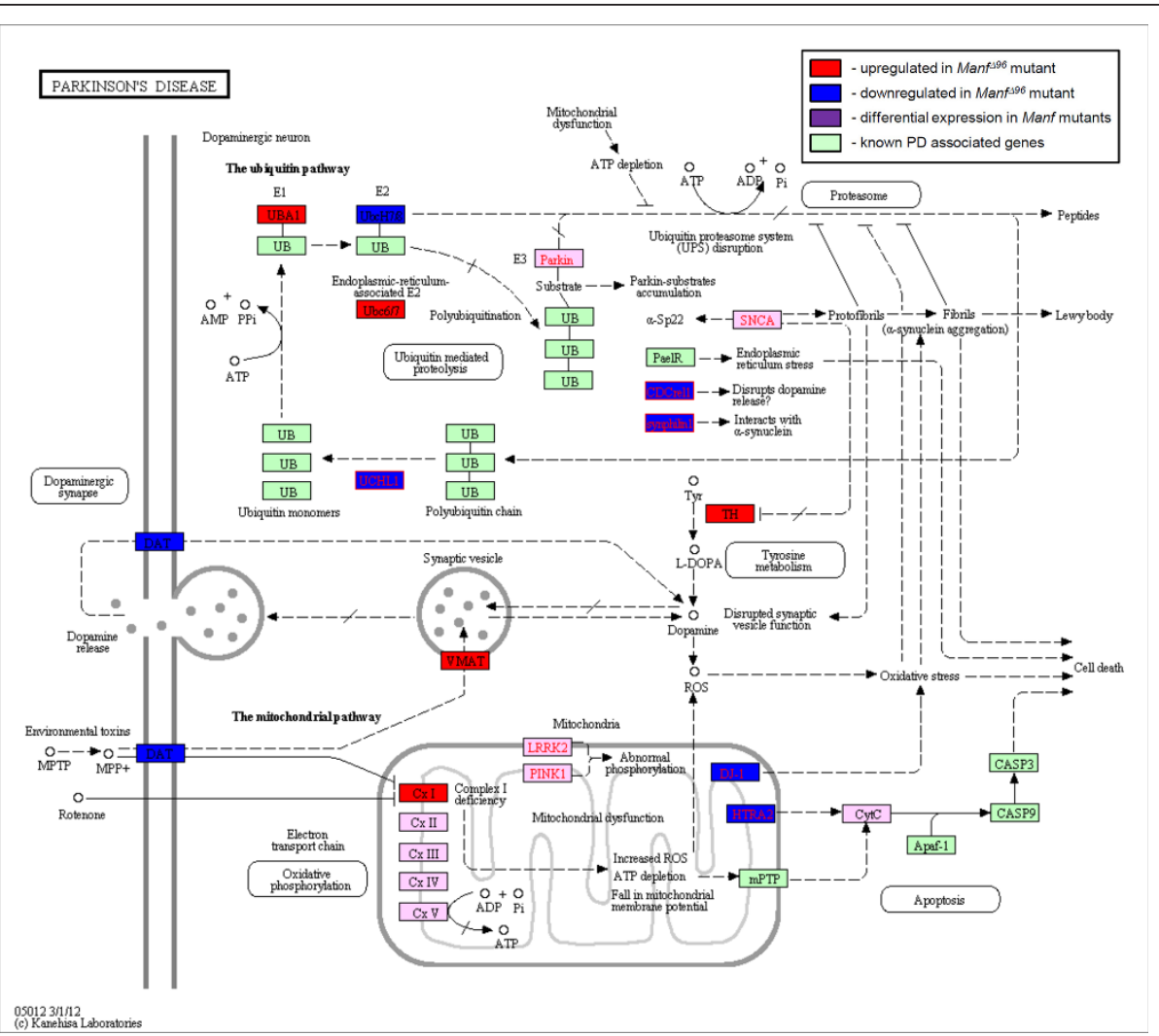

Figure 5 Gene expression alterations in Manf mutants with a linkage to Parkinson's disease. A human disease KEGG pathway coloured with Drosophila homologues showing altered gene expression in Manf mutants - filled boxes with red represent genes that are upregulated, with blue downregulated expression or with purple differently altered gene expression between two Manf mutants. The unaltered components in the pathway are coloured green. Note that $\alpha$-synuclein (SNCA) has no homologue in Drosophila. The complete list of altered genes is summarised in Table 11 with some additional genes not present in KEGG pathway but have been associated with PD elsewhere. The expression of genes with a role in dopamine uptake, intracellular transport, and synthesis is altered. Mitochondrial oxidative pathway complex I encoding genes show upregulation. The other mitochondrial proteins encoded by nuclear genes involved in PD such as Htra2 and DJ-1 expression is downregulated in Manf mutants. Some members of ubiquitin pathway are altered as well.

synthesis (ple coding for $\mathrm{TH}, \mathrm{Ddc}$, and punch) were differentially expressed (Table 2, Additional File 1). The expression of many genes involved in mitochondria and ubiquitin proteasome pathways were also altered. Increasing evidence indicates that organelle stress is a key event in neurodegeneration [14]. UPR is an adaptive process aiming to restore the cell homeostasis under ER stress conditions and to re-establish the properly folded protein synthesis. Under irreversible ER damage UPR initiates cell death pathway to eliminate damaged cells. Manf could be responsible for the recovery and survival pathway in UPR. In this scenario, the lack of Manf especially in the secretory cells with high rates of protein synthesis, including neurons with intensive neurotransmission, might result in shift from ER stress to UPR towards cell death. However, the mechanism how Manf dispatches this function is still unclear. Recently the structural homology between the Manf C-terminal folding and SAP domain of Ku70 has been demonstrated [34]. SAP domain of Ku70 is known to inhibit Baxinduced apoptosis [35] and in vitro experiments with mammalian cultured neurons showed that Manf rescues the NGF-deprivation induced cell death as efficiently as Ku70 itself [34]. On the other hand we showed that the overexpression of Manf resulted in upregulation of genes involved in oxidation reduction. The DA neurons are known to be very sensitive to oxidative stress because dopamine metabolites are highly oxidative compounds [36]. Therefore the upregulation of genes responsible for oxidation reduction could be already protective for DA neurons. Besides reactive dopamine metabolites, the mitochondrial dysfunction has been implicated in the neurodegeneration occurring in PD. We found that, in Manf ${ }^{m z \Delta 96}$ mutants with degenerating DA neurites, the nuclear genes coding for mitochondrial proteins were significantly enriched among the downregulated genes. 
Table 11 List of genes with altered expression according to microarray analysis related to KEGG pathway of Parkinson's disease

\begin{tabular}{|c|c|c|c|c|c|c|c|}
\hline \multirow{2}{*}{$\begin{array}{l}\text { KEGG } \\
\text { name }\end{array}$} & \multirow{2}{*}{$\begin{array}{l}\text { Human } \\
\text { gene }\end{array}$} & \multicolumn{2}{|c|}{ embryo } & \multicolumn{2}{|c|}{ larvae } & \multicolumn{2}{|l|}{ Flybase } \\
\hline & & o.ex. & mut. & o.ex. & mut. & ID & Description \\
\hline $\mathrm{TH}$ & $\mathrm{TH}$ & & up & & & CG10118 & pale, tyrosine hydroxylase \\
\hline VMAT & VMAT & & & & up & CG6139 & vesicular monoamine transporter \\
\hline DAT & SCL6A3 & up & down & & & CG8380 & dopamine transporter \\
\hline HTRA2 & HTRA2 & up & down & & & CG8464 & HtrA serine peptidase 2 \\
\hline NDUFV1 & NDUFV1 & up & down & & & CG9140 & NADH dehydrogenase \\
\hline SNCAIP & SNCAIP & & & up & down & CG5424 & forked, actin binding $\alpha$ synuclein interacting \\
\hline CDCREL1 & PNUTL1 & & & up & down & CG7238 & septin interacting protein 1 \\
\hline CytC & CYCS & & & up & down & CG14235 & cytochrome-c oxidase \\
\hline \multirow[t]{3}{*}{ UQCRH } & UQCRH & up & & up & down & CG30354 & ubiquinol-cytochrome-c reductase \\
\hline & SIP2 & & & up & down & CG9188 & septin interacting protein 2 \\
\hline & SLC25A6 & & & up & down & CG1683 & mitochondrial adenine nucleotide translocase 2 \\
\hline Uchl1 & UCHL & & & up & & CG4265 & Ubiquitin carboxy-terminal hydrolase \\
\hline $\mathrm{mPTP}$ & VDAC2 & up & up & up & down & CG17137 & Porin2, voltage-gated anion channel \\
\hline ATPase & ATP5EP2 & & & up & & CG31477 & mitochondrial ATPase $\varepsilon$ subunit, F1 complex \\
\hline \multirow[t]{2}{*}{ NDUFA2 } & NDUFA2 & & & up & up & CG15434 & NADH dehydrogenase \\
\hline & SEP4 & & up & & up & CG9699 & Septin 4 \\
\hline Ube2J2 & UBE2J2 & & & down & up & CG5823 & ubiquitin-protein ligase \\
\hline \multirow[t]{2}{*}{ NDUFV2 } & NDUFV2 & & & & up & CG5707 & NADH dehydrogenase \\
\hline & UBE2H & & & & up & CG2257 & Ubc-E2H, ubiquitin-protein ligase \\
\hline \multirow[t]{2}{*}{ Ube2L3 } & UBE2L3 & & & down & down & CG12799 & Ubiquitin conjugating enzyme 84D \\
\hline & UBQLN1 & & & down & & CG14224 & EF1B ubiquitin-assoc. translation elongation factor \\
\hline \multirow[t]{3}{*}{ Ubh4 } & UCHL & & & & down & CG3431 & Ubiquitin C-terminal hydrolase \\
\hline & USP36 & & & & down & CG5505 & scrawny, ubiquitin protease \\
\hline & SIP3 & & & & down & CG1937 & septin interacting protein 3 \\
\hline Uba1 & UBA1 & & up & & & CG1782 & ubiquitin activating enzyme 1 \\
\hline \multirow[t]{3}{*}{ CytC } & CYCS & up & up & & & CG2249 & cytochrome-c oxidase \\
\hline & SEP1 & & up & & & CG1403 & Septin-1 \\
\hline & UBE2E2 & & up & & & CG6720 & Ubiquitin conjugating enzyme 2 \\
\hline DJ-1 & $D J-1$ & & down & & & CG6646 & DJ-1 $\alpha$ \\
\hline CytC & CYCS & & down & & & CG13263 & cytochrome c distal \\
\hline CytC & CYCS & & down & & & CG14028 & cyclope, cytochrome-c oxidase \\
\hline CytC & CYC1 & & down & & & CG4769 & electron transporter \\
\hline ATPase & ATP5G2 & down & down & & & CG1746 & hydrogen-exporting ATPase \\
\hline ATPase & ATP5E & & down & & & CG9032 & stunted, hydrogen-exporting ATPase \\
\hline
\end{tabular}

Significant alterations in gene expression from wild type are shown by word code; "up" represents upregulation and "down" downregulation of gene expression. Notice that the same KEGG identifier can lead to several different genes. Several Drosophila genes associated with processes in PD missing from KEGG pathway were added. The according coloured scheme for Parkinson's disease KEGG pathway is presented in Figure 5.

\section{Conclusions}

We have studied the gene expression changes of two slightly different Manf mutants in Drosophila. Surprisingly, the expression profiles of embryonic lethal Manf ${ }^{m z \Delta 96}$ and larval lethal Manf ${ }^{196}$ mutants were quite diverse. It might be due to the dissimilar roles of Manf gene during embryonic and larval stages or it indicates the difference between the absolute lack of Manf versus gradual diminishing of maternally contributed stores of Manf gene products. Our microarray analysis followed by functional annotation clustering revealed statistically significant enrichment related to metabolism and membrane transport and transporters. The observed changes in membrane traffic were supported by ultrastructural studies of Manf $f^{m z \Delta 96}$ mutant. More than $40 \%$ of known Drosophila genes related to ER and UPR showed altered 
expression levels in Manf mutants. We found changed expression of several genes known to be associated with processes altered in PD such as oxidative phosphorylation, mitochondrial function, dopamine metabolism and uptake, and protein ubiquitinaton. The lack of Manf in Manf ${ }^{\text {nz } \Delta 96}$ mutant embryos resulted in massive upregulation of stress, defense, and immune response related genes as well as genes involved in proteolysis and cell death. Overexpression of Manf resulted in upregulation of genes involved in oxidation reduction, an important process to protect DA neurons from oxidative stress. Thus, our results support the previously reported findings in mammalian cells that upregulation of Manf is important in UPR and could be protective for the cell. It is also evident that ER stress leads to UPR and cell death in the absence of Manf. These effects were less drastic when Manf was gradually abolished in Manf $f^{496}$ mutant larvae and related to several metabolic processes and downregulation of genes involved in replication, transcription and splicing. Still, stress and defense related genes were enriched among the upregulated genes of both Manf mutants.

\section{Methods}

\section{Fly strains}

Drosophila melanogaster adults were maintained at $25^{\circ} \mathrm{C}$ on malt and wholemeal flour based standard food, for egg laying apple juice agar plates with yeast paste were used. Wild type flies were $w^{-}$, all genotypes used were of $w^{-}$background: hs $70 F l p /+; ; F R T^{82 B} \mathrm{Manf}^{496} / \mathrm{Manf}^{196}$, Manf ${ }^{466} / T M 3$ Sb Ser twi > GFP. For ectopic overexpression 69B-GAL4 [37] and UAS-DmManf ${ }^{l 33}$ ( $3^{\text {rd }}$ chromosome insertion) were used. As an ER marker ER-targeted $s q h$-EYFP flies were used. UAS-GFP-rab5, UAS-GFPrab11, UAS-chc-GFP, and UAS-GFP-rab7 were obtained from C. Samakovlis and $p p l>$ GAL4 from V. Hietakangas. Other fly lines were obtained from Bloomington Drosophila Stock Center or generated by us [5].

\section{RNA isolation}

For RNA extraction, embryos were collected from apple juice plates, washed with embryowash, dechorionated by standard bleach treatment and washed thoroughly. Both embryos and larvae were separated and picked by phenotype and staged under microscope onto fresh apple juice plates, collected into Eppendorf tubes and snap frozen. Total RNA was extracted with Qiagene RNAeasy extraction Kit (Qiagene) according to manufacturer's recommendations, treated with RNase-free DNase (Promega) 15 min at $37^{\circ} \mathrm{C}$ and purified by RNA clean-up kit (MachereyNagel). RNA was quantified using a NanoDrop-1000 spectrophotometer and RNA quality was monitored by the Agilent 2100 Bioanalyzer (Agilent Technologies).

\section{Microarray experiments}

For microarray experiment three biologically independent samples for each genotype were used. Diluted spike controls (Agilent) were added to $1 \mu \mathrm{g}$ of total RNA samples and in vitro transcribed and labeled with Amino Allyl MessageAmp ${ }^{\mathrm{TM}}$ II aRNA Amplification Kit (Ambion/Applied Biosystems). The dyes used were cyanine 3 (Cy3), cyanine 5 (Cy5) or Alexa 488, as previously described [38]. Dye incorporation and received aaRNA yield were monitored by the NanoDrop ND1000 Spectrophotometer.

\section{Hybridisation}

$5 \mu \mathrm{g}$ of each differentially labelled aaRNA was fragmented at $60^{\circ} \mathrm{C}$ for $30 \mathrm{~min}$ in a reaction volume of $55 \mu \mathrm{l}$ containing Agilent fragmentation buffer and 2x Agilent blocking agent following the manufacturer's instructions. On completion of the fragmentation reaction, $55 \mu \mathrm{l}$ of $2 \mathrm{x}$ Agilent hybridization buffer was added to the fragmentation mixture and hybridized to Agilent's fruit fly Microarray Kit 4x44k, P/N G2519F (Agilent Microarray Design ID 018972) for 17 hours at $65^{\circ} \mathrm{C}$ in a rotating Agilent hybridization oven. After hybridization, microarrays were washed $1 \mathrm{~min}$ at room temperature with GE Wash Buffer 1 (Agilent) and 1 min with $37^{\circ} \mathrm{C}$ GE Wash buffer 2 (Agilent), then dried immediately by brief centrifugation. The slides were then scanned by Axon 4200AL scanner.

\section{DNA microarray analysis}

The microarrays images were segmented and the median intensity of each spot was estimated by the software GenePixPro $^{\circledR} 6.0$ (Axon). The data were then imported into R software http://cran.r-project.org/ and preprocessed by the BioConductor package Limma [39]. Linear model followed by moderated t-test was utilized for finding the differentially expressed genes ( $\mathrm{P}$-value $<0.01$ after Benjamini and Hochberg correction) between Manf ${ }^{\Delta 96}$, Manf $^{m z \Delta 96}$, Manf $^{m \Delta 96} /+, 69 B>$ Manf $^{133}$ and $w^{-}$. Lists of significant genes were screened by the DAVID 6.7 annotation tools $[40,41]$ in order to find over-represented biological themes. Default DAVID parameters were used. To identify the pathways altered, the online tool available from Kanehisa laboratories, KEGG Mapper was used [42]. All microarray data are MIAME compliant and available at the NCBI GEO database (ID GSE28820).

\section{Quantitative PCR}

For qPCR, independent biological samples were used for RNA extraction. $4 \mu \mathrm{g}$ of total RNA was reverse transcribed with MMLV reverse transcriptase (Promega) according to manufacturer's instructions using oligo(dT) 
primers. The primers were designed with the help of Universal ProbeLibrary Assay Design System (Roche Applied Science) and are listed in Additional file 16. qPCR was performed with Lightcycler 480 real-time PCR system (Roche Diagnostics) with the help of pipeting robot Robotics4 (Corbett Robotics) on 384-well plates using Lightcycler 480 SYBR Green I Master complemented with 5 pmol of primers and cDNA corresponding to $40 \mathrm{ng}$ of total RNA used in reverse transcription. Three replicates for each reaction were included in the PCR runs. Results were analysed with Lightcycler software version 1.5.0.39.

\section{Transmission electron microscopy and immunohistochemistry}

The embryos for TEM were treated as previously described [43]. The whole larvae were subjected to high pressure freezing to visualise the cuticle layers as described earlier [44]. The primary antibodies used were rabbit phospho-eIF2 $\alpha$ (Ser51) antibody (1:1000, Cell Signaling Technology), mouse $\alpha$-DmTubulin (1:1000, Sigma) and rabbit $\alpha$-DmManf (1:1000) [5]. Immunohistochemistry and imaging were performed as previously described [5]. To visualise the lysosomes, Lysotracker Red DND99 (Invitrogen) was used. The red colour of Alexa568 dye was changed to magenta in order to help colour blind people to distinguish it in the combinations with green.

\section{Western blotting}

For Western blotting about 100 embryos of stage 17 were collected, genotyped, and homogenised in $10 \mathrm{mM}$ HEPES, $1 \mathrm{mM}$ EDTA, $0.25 \mathrm{M}$ sucrose homogenising buffer, $\mathrm{pH}=7.3$ in the presence of protease inhibitor cocktail (Complete Mini, Roche). The concentration of proteins was measured with Bio Rad protein assay $D_{C}$ reagents. The equal amounts of total protein were mixed with $3 \times$ Laemmli loading buffer and boiled at $99^{\circ} \mathrm{C}$ for five minutes. Up to $6 \mu \mathrm{g}$ of total protein were loaded per lane to SDS-acrylamide gel. Western blotting was further proceeded according to the standard manufacturer's instructions (Amersham Biosciences). For the quantification of Western blotting results ImageJ analysis software was used. Quantification was based on area measurements and intensity calculations in comparison with the anti-tubulin loading control.

\section{Additional material}

Additional file 1: Table of all obtained qPCR results. The Excel file contains two separate sheets, one for the data obtained from stage 17 embryos and the other for the data obtained from 29-50 hr AEL larvae.

Additional file 2: DAVID functional annotation clustering analysis of downregulated genes in embryonic Manf ${ }^{m z \Delta 96}$ mutants. An Excel file;
1191 genes were downregulated and grouped into 105 functional clusters.

Additional file 3: DAVID functional annotation clustering analysis of upregulated genes in embryonic Manf ${ }^{m z \Delta 96}$ mutants. An Excel file;

1243 genes were upregulated and grouped into 230 functional clusters.

Additional file 4: DAVID functional annotation clustering analysis of

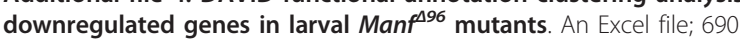
genes were downregulated and grouped into 140 functional clusters.

Additional file 5: DAVID functional annotation clustering analysis of upregulated genes in larval Manf ${ }^{996}$ mutants. An Excel file; 682 genes were upregulated and grouped into 122 functional clusters.

Additional file 6: DAVID functional annotation clustering analysis of common downregulated genes in Manf ${ }^{m z \Delta 96}$ and Manf ${ }^{496}$ mutants. An Excel file; 208 genes were downregulated in both Manf mutants and grouped into 47 functional clusters.

Additional file 7: DAVID functional annotation clustering analysis of common upregulated genes in Manf ${ }^{m z \Delta 96}$ and Manf ${ }^{\Delta 96}$ mutants. An Excel file; 229 genes were upregulated in both Manf mutants and grouped into 45 functional clusters.

Additional file 8: Exocytosis and SNARE complex is altered in Manf mutants. A pdf file; an online coloured KEGG pathway showing altered gene expression in either red (upregulation), blue (downregulation), or in purple (altered gene expression) boxes. The unaltered known Drosophila homologues to identified components from other organisms are presented in green-filled boxes. The complete list of altered genes is summarised in Table 8.

Additional file 9: Lysosomal degradation is altered in Manf mutants. A pdf file; an online coloured KEGG pathway showing altered gene expression in either red (upregulation), blue (downregulation), or in purple (altered gene expression) boxes. The unaltered known Drosophila homologues to identified components from other organisms are presented in green-filled boxes. The complete list of altered genes is summarised in Table 10.

Additional file 10: DAVID functional annotation clustering analysis of upregulated genes in $M a n f^{m z \Delta 96}$ mutant paternal rescue. An Excel file; 98 genes were upregulated when maternal lack of Manf gene products was rescued paternally and grouped into 18 functional clusters.

Additional file 11: DAVID functional annotation clustering analysis of downregulated genes in Manf ${ }^{m z \Delta 96}$ mutant paternal rescue. An Excel file; only 34 genes were downregulated when maternal lack of Manf gene products was rescued paternally and grouped into 4 functional clusters.

Additional file 12: DAVID functional annotation clustering analysis of upregulated genes in Manf ectopic overexpression by 69B-GAL4. An Excel file; 614 genes were upregulated and grouped into 102 functional clusters.

Additional file 13: DAVID functional annotation clustering analysis of downregulated genes in Manf ectopic overexpression by $69 B$ GAL4. An Excel file; 340 genes were downregulated and grouped into 78 functional clusters.

Additional file 14: DAVID functional annotation clustering analysis of common upregulated genes in Manf ${ }^{m z \Delta 96}$ paternally rescued embryos and in Manf ectopically overexpressing larvae. An Excel file; 57 genes were upregulated in both Manf mutants and grouped into 9 functional clusters, $14 \mathrm{GO}$ terms remained unclustered.

Additional file 15: Complete list and DAVID functional annotation clustering analysis of genes downregulated in Manf ${ }^{\triangle 96}$ mutants and upregulated in Manf ectopic overexpression and vice versa. An Excel file; 46 genes were downregulated in larval Manff96 mutants and upregulated in Manf ectopic overexpression, vice versa 16 genes were upregulated in Manf ${ }^{196}$ mutants and downregulated in Manf ectopic overexpression. In the first sheet complete list of genes together with fold change logarithmic ( $\mathrm{FClog}$ ) results is presented. In the second sheet results of DAVID functional annotation clustering analysis with 9 clusters is shown.

Additional file 16: List of all designed primers used for qPCR 


\section{Acknowledgements}

We thank Mart Saarma, Päivi Lindholm, Osamu Shimmi, Christos Samakovlis and Ville Hietakangas for reagents and fly stocks, Eeva-Marja Turkki for the technical assistance, Jouni Kvist, Panu Somervuo, Petri Törönen, and Ilya Plyusnin for the comments and help with microarray analysis, Mikko Airavaara for the help with Western blot quantifications, Juha Partanen and Johan Peränen for critical comments during the writing of the manuscript. This work was supported by the Academy of Finland Neuroscience Program, the Michael J. Fox Foundation, the Finnish Parkinson Foundation and the University of Helsinki research funds.

\section{Author details}

'Department of Biosciences, University of Helsinki, PO Box 56, Viikinkaari 5, Helsinki 00014, Finland. ${ }^{2}$ Institute of Biotechnology, University of Helsinki, PO Box 56, Viikinkaari 9, Helsinki 00014, Finland. ${ }^{3}$ Department of Bioscience and Nutrition, Karolinska Institutet, Stockholm, Sweden.

\section{Authors' contributions}

$M P, T I H, D G$, and PA designed the research, MP performed the laboratory experiments, DG scanned the slides and made the analysis and comparisons of the raw scanned microarray data, MP with the help of RL completed the annotation, and MP made functional annotation clustering analysis, all other laboratory experiments and wrote the draft manuscript. All authors read, made corrections and approved the manuscript.

\section{Competing interests}

The authors declare that they have no competing interests.

Received: 16 June 2011 Accepted: 11 April 2012

Published: 11 April 2012

\section{References}

1. Lindholm P, Saarma M: Novel CDNF/MANF family of neurotrophic factors. Dev Neurobiol 2010, 70:360-371.

2. Petrova P, Raibekas A, Pevsner J, Vigo N, Anafi M, Moore MK, Peaire AE, Shridhar V, Smith DI, Kelly J, Durocher Y, Commissiong JW: MANF: a new mesencephalic, astrocyte-derived neurotrophic factor with selectivity for dopaminergic neurons. J Mol Neurosci 2003, 20:173-188.

3. Lindholm $\mathrm{P}$, Voutilainen $\mathrm{MH}$, Laurén J, Peränen J, Leppänen VM, Andressoo JO, Lindahl M, Janhunen S, Kalkkinen N, Timmusk T, Tuominen RK, Saarma M: Novel neurotrophic factor CDNF protects and rescues midbrain dopaminergic neurons in vivo. Nature 2007, 448:73-77.

4. Voutilainen $M H$, Back S, Pörsti E, Toppinen $L$, Lindgren $L$, Lindholm P, Peränen J, Saarma M, Tuominen RK: Mesencephalic astrocyte-derived neurotrophic factor is neurorestorative in rat model of Parkinson's disease. J Neurosci 2009, 29:9651-9659.

5. Palgi M, Lindström R, Peränen J, Piepponen TP, Saarma M, Heino Tl: Evidence that DmMANF is an invertebrate neurotrophic factor supporting dopaminergic neurons. Proc Natl Acad Sci USA 2009, 106:2429-2434.

6. Mizobuchi N, Hoseki J, Kubota H, Toyokuni S, Nozaki J, Naitoh M, Koizumi A, Nagata K: ARMET is a soluble ER protein induced by the unfolded protein response via ERSE-II element. Cell Struct Funct 2007, 32:41-50.

7. Apostolou A, Shen Y, Liang Y, Luo J, Fang S: Armet, a UPR-upregulated protein, inhibits cell proliferation and ER stress-induced cell death. Exp Cell Res 2008, 314:2454-2467.

8. Tadimalla A, Belmont PJ, Thuerauf DJ, Glassy MS, Martindale JJ, Gude N, Sussman MA, Glembotski CC: Mesencephalic astrocyte-derived neurotrophic factor is an ischemia-inducible secreted endoplasmic reticulum stress response protein in the heart. Circ Res 2008, 103:1249-1258.

9. Lindholm P, Peränen J, Andressoo JO, Kalkkinen N, Kokaia Z, Lindvall O, Timmusk T, Saarma M: MANF is widely expressed in mammalian tissues and differently regulated after ischemic and epileptic insults in rodent brain. Mol Cell Neurosci 2008, 39:356-371.

10. Airavaara M, Shen H, Kuo CC, Peränen J, Saarma M, Hoffer B, Wang Y: Mesencephalic astrocyte-derived neurotrophic factor reduces ischemic brain injury and promotes behavioral recovery in rats. $J$ Comp Neurol 2009, 515:116-124.

11. Ron $D$, Walter $P$ : Signal integration in the endoplasmic reticulum unfolded protein response. Nat Rev Mol Cell Biol 2007, 8:519-529.
12. Bertolotti A, Zhang $Y$, Hendershot LM, Harding HP, Ron D: Dynamic interaction of BiP and ER stress transducers in the unfolded-protein response. Nat Cell Biol 2000, 2:326-332.

13. Shen J, Chen X, Hendershot L, Prywes R: ER stress regulation of ATF6 localization by dissociation of BiP/GRP78 binding and unmasking of Golgi localization signals. Dev Cell 2002, 3:99-111.

14. Matus S, Lisbona F, Torres M, Leon C, Thielen P, Hetz C: The stress rheostat: an interplay between the unfolded protein response (UPR) and autophagy in neurodegeneration. Curr Mol Med 2008, 8:157-172.

15. Hoozemans JJ, van Haastert ES, Eikelenboom P, de Vos RA, Rozemuller JM, Scheper W: Activation of the unfolded protein response in Parkinson's disease. Biochem Biophys Res Commun 2007, 354:707-711.

16. Ryoo HD, Domingos PM, Kang MJ, Steller H: Unfolded protein response in a Drosophila model for retinal degeneration. EMBO J 2006, 26:242-252.

17. Rasheva VI, Domingos PM: Cellular responses to endoplasmic reticulum stress and apoptosis. Apoptosis 2009, 14:996-1007.

18. Chan HY, Bonini NM: Drosophila models of human neurodegenerative disease. Cell Death Differ 2000, 7:1075-1080.

19. Malzer E, Daly M, Moloney A, Sendall TJ, Thomas SE, Ryder E, Ryoo HD, Crowther DC, Lomas DA, Marciniak SJ: Impaired tissue growth is mediated by checkpoint kinase 1 (CHK1) in the integrated stress response. J Cell Sci 2010, 123:2892-2900.

20. Girardot F, Monnier V, Tricoire H: Genome wide analysis of common and specific stress responses in adult Drosophila melanogaster. BMC Genomics 2004, 5:74.

21. Wigglesworth VB: The Principles of Insect Physiology: 7th ed London: Chapman and Hall; 1972.

22. Forjanic JP, Chen CK, Jackle H, Gonzalez Gaitan M: Genetic analysis of stomatogastric nervous system development in Drosophila using enhancer trap lines. Dev Biol 1997, 186:139-154.

23. Senderek J, Krieger M, Stendel C, Bergmann C, Moser M, Breitbach-Faller N, Rudnik-Schoneborn S, Blaschek A, Wolf NI, Harting I, North K, Smith J, Muntoni F, Brockington M, Quijano-Roy S, Renault F, Herrmann R, Hendershot LM, Schroder JM, Lochmuller H, Topaloglu H, Voit T, Weis J, Ebinger F, Zerres K: Mutations in SIL1 cause Marinesco-Sjogren syndrome, a cerebellar ataxia with cataract and myopathy. Nat Genet 2005, 37:1312-1314.

24. Tadimalla A: Discovery of mesencephalic astrocyte-derived neurotrophic factor (MANF) as a secreted, endoplasmic reticulum stress responseinduced gene, and its role in the heart. PhD University of California, San Diego and San Diego State University, UMI, ProQuest; 2010.

25. Sood R, Porter AC, Ma K, Quilliam LA, Wek RC: Pancreatic eukaryotic initiation factor-2alpha kinase (PEK) homologues in humans, Drosophila melanogaster and Caenorhabditis elegans that mediate translational control in response to endoplasmic reticulum stress. Biochem J 2000, 346(Pt 2):281-293.

26. Pomar N, Berlanga JJ, Campuzano S, Hernandez G, Elias M, de Haro C: Functional characterization of Drosophila melanogaster PERK eukaryotic initiation factor 2alpha (elF2alpha) kinase. Eur J Biochem 2003, 270:293-306.

27. Olsen DS, Jordan B, Chen D, Wek RC, Cavener DR: Isolation of the gene encoding the Drosophila melanogaster homolog of the Saccharomyces cerevisiae GCN2 elF-2alpha kinase. Genetics 1998, 149:1495-1509.

28. Woehlbier U, Hetz C: Modulating stress responses by the UPRosome: a matter of life and death. Trends Biochem Sci 2011, 36:329-337.

29. Payre F: Genetic control of epidermis differentiation in Drosophila. Int J Dev Biol 2004, 48:207-215.

30. Moussian B, Veerkamp J, Muller U, Schwarz H: Assembly of the Drosophila larval exoskeleton requires controlled secretion and shaping of the apical plasma membrane. Matrix Biol 2007, 26:337-347.

31. Moussian B, Soding J, Schwarz H, Nusslein-Volhard C: Retroactive, a membrane-anchored extracellular protein related to vertebrate snake neurotoxin-like proteins, is required for cuticle organization in the larva of Drosophila melanogaster. Dev Dyn 2005, 233:1056-1063.

32. Moussian B, Schwarz H, Bartoszewski S, Nusslein-Volhard C: Involvement of chitin in exoskeleton morphogenesis in Drosophila melanogaster. J Morphol 2005, 264:117-130.

33. Moussian B, Tang E, Tonning A, Helms S, Schwarz H, Nusslein-Volhard C, Uv AE: Drosophila Knickkopf and Retroactive are needed for epithelial tube growth and cuticle differentiation through their specific requirement for chitin filament organization. Development 2006, 133:163-171. 
34. Hellman M, Arumäe U, Yu LY, Lindholm P, Peränen J, Saarma M, Permi P: Mesencephalic Astrocyte-derived Neurotrophic Factor (MANF) Has a Unique Mechanism to Rescue Apoptotic Neurons. J Biol Chem 2011, 286:2675-2680

35. Amsel AD, Rathaus M, Kronman N, Cohen HY: Regulation of the proapoptotic factor Bax by Ku70-dependent deubiquitylation. Proc Nat Acad Sci USA 2008, 105(13):5117-5122.

36. Cadet $\mathrm{J}$, Brannock $\mathrm{C}$ : Free radicals and the pathobiology of brain dopamine systems. Neurochem Int 1998, 32:117-131.

37. Brand $\mathrm{AH}$, Perrimon $\mathrm{N}$ : Targeted gene expression as a means of altering cell fates and generating dominant phenotypes. Development 1993 118:401-415.

38. Pessa HK, Greco D, Kvist J, Wahlstrom G, Heino TI, Auvinen P, Frilander MJ. Gene expression profiling of U12-type spliceosome mutant Drosophila reveals widespread changes in metabolic pathways. PLoS One 2010, 5 e13215.

39. Smyth GK: Linear models and empirical bayes methods for assessing differential expression in microarray experiments. Stat Appl Genet Mol Biol 2004, 3:Article 3.

40. Dennis G Jr, Sherman BT, Hosack DA, Yang J, Gao W, Lane HC, Lempicki RA DAVID: Database for Annotation, Visualization, and Integrated Discovery. Genome Biol 2003, 4:P3.

41. da Huang W, Sherman BT, Lempicki RA: Systematic and integrative analysis of large gene lists using DAVID bioinformatics resources. Nat Protoc 2009, 4:44-57.

42. Kanehisa M, Goto S, Furumichi M, Tanabe M, Hirakawa M: KEGG for representation and analysis of molecular networks involving diseases and drugs. Nucleic Acids Res 2010, , 38 Database: D355-360.

43. Budnik V, Gorczyca M, Prokop A: Selected methods for the anatomical study of Drosophila embryonic and larval neuromuscular junctions. Int Rev Neurobiol 2006, 75:323-365.

44. Moussian B, Seifarth C, Muller U, Berger J, Schwarz H: Cuticle differentiation during Drosophila embryogenesis. Arthropod Struct Dev 2006, 35:137-152.

doi:10.1186/1471-2164-13-134

Cite this article as: Palgi et al:: Gene expression analysis of Drosophilaa

Manf mutants reveals perturbations in membrane traffic and major metabolic changes. BMC Genomics 2012 13:134

\section{Submit your next manuscript to BioMed Central and take full advantage of:}

- Convenient online submission

- Thorough peer review

- No space constraints or color figure charges

- Immediate publication on acceptance

- Inclusion in PubMed, CAS, Scopus and Google Scholar

- Research which is freely available for redistribution

Submit your manuscript at www.biomedcentral.com/submit 